\title{
Study on the Permeability Evolution and Its Formation Mechanism of Xiaojihan Aquifer Coal Seam under Plastic Flow
}

\author{
Jingna Guo $\mathbb{D}^{1,2}$ Jiangfeng Liu $\mathbb{D},{ }^{1,2}$ Qiang Li, ${ }^{1}$ and Zhanqing Chen $\mathbb{D}^{1}$ \\ ${ }^{1}$ State Key Laboratory for Geomechanics and Deep Underground Engineering, And School of Mechanics and Civil Engineering, \\ China University of Mining and Technology, Xuzhou 221116, China \\ ${ }^{2}$ Key Laboratory of Mining Disaster Prevention and Control, Shandong University of Science and Technology, \\ Qingdao 266590, China
}

Correspondence should be addressed to Jiangfeng Liu; rayna182@163.com

Received 2 December 2019; Accepted 7 January 2020; Published 15 February 2020

Academic Editor: Paolo Fulignati

Copyright (C) 2020 Jingna Guo et al. This is an open access article distributed under the Creative Commons Attribution License, which permits unrestricted use, distribution, and reproduction in any medium, provided the original work is properly cited.

Study on permeability evolution of an aquifer coal seam in Western China is of great significance for preventing water inrush disaster and realizing water-conserving coal mining. The permeability evolution of an aquifer coal seam is related to a loading path closely under plastic flow. In this work, permeability variations of the Xiaojihan water-bearing coal seam and Longde nonwater coal seam are researched using a transient method under plastic flow. The experiment results indicated the following: (1) Under the same axial strain, the permeability, relative residual strain, and confining pressure influence coefficient of Xiaojihan coal specimens all decrease in plastic flow with the increase of loading-unloading times and confining pressure, while the permeability recovery coefficient increases during this process. (2) The permeability of Xiaojihan water-bearing coal specimens decreases with the growth of axial strain in plastic flow, resulting in the increase of relative residual strain and reinforcement of plasticity. Besides, the confining pressure influence coefficient decreases and the permeability recovery coefficient decreases slightly with the axial strain. (3) Finally, the permeability of Xiaojihan coal specimens is greater than that of Longde coal specimens, while the confining pressure influence coefficient and permeability recovery coefficient of Longde coal specimens are greater than those of Xiaojihan coal specimens. The closure rate of internal cracks of the water-bearing coal specimen is lower than that of the nonwater coal specimen, which is beneficial for water storage and transport.

\section{Introduction}

It is necessary to set up safe coal pillars with different supporting and isolating functions during coal seam excavation. In the excavation process, plastic flow occurs in some areas of a coal pillar after shear yield occurring in these areas, and the deformation of coal pillars causes the change of permeability correspondingly. Multiple redistribution of the stress field also leads to the coal pillar being continuously in the abutment pressure area or pressure relief area; that is to say, the coal pillar is under a cyclic loading and unloading process. Actually, cyclic loading and unloading loads are common in the underground engineering [1-4]. For example, the front coal body is affected by the periodic breaking of the overlying basic rock stratum structure in the mining process of the coal mining face, and the moving support pressure on the work- ing face shows obvious periodicity. Coal outburst and coal caving support lifting and crushing of top coal caused by unloading confining pressure generated when Shimen is connected to coal. In fact, it is a process of repeated loading and unloading of coal, and unloading is more likely to cause instability of coal rock.

The Xiaojihan coal mine is located in the northeastern part of the nationally planned Jurassic coalfield in the northern Shanxi Province, located in Xiaojihan Township, Yuyang District, Yulin City. It is the first 10-million-ton modernized mine in the Yanheng mining area. Its main recoverable coal seam is No. 2 and No. 4-2 coal seams. With the development of the Xiaojihan coal mine, China's coal mines were first discovered, especially in the western mining areas. The mining coal seam is a special geological phenomenon of the main aquifer of the mine. According to the actual measurement, 
the water inflow from the minefield is mainly the aquifer water of the No. 2 coal seam, accounting for more than $80 \%$ of the total water inflow of the mine. Since the No. 2 coal seam developed is a high-pressure aquifer [5], the original geological exploration report is far from the actual situation, causing water accumulation or flood disaster in roadways easily.

The brittle failure occurs in the ordinary coal pillars due to its low water content, while plastic behavior is observed obviously in the Xiaojihan coal mine with coal seam as the main aquifer [6-8]. Under the repeated action of mining disturbance, the plastic zone of the coal pillar expands continuously, and plastic flow occurs at various points in the plastic zone. The deformation of the coal pillar induces the variation of porosity and permeability. It is worth noting that the permeability of the coal pillar in the plastic zone is dependent on its stress-strain state, but the single value corresponding relationship between permeability and strain is no longer existing. Meanwhile, the position of phase points in the plastic zone is determined by the flow path. Thus, the permeability of the coal pillar after failure depends not only on the current stress-strain state but also on the plastic flow path of points in the coal pillar plastic zone. It is necessary to study the permeability of coal by understanding the evolution of permeability under various hysteresis loops.

The coal measured rock is under different stress states and levels due to mining excavation. In order to study the evolution of permeability of coal measured rock under different stress states and levels, lots of experiments are conducted to study the mechanism of permeability, especially focused on the relation between permeability and stress-strain curve, as well as the relation between permeability and confining pressure. Permeability tests of coal measured rock during the whole stress-strain process were conducted by scholars [9-15] indicating that permeability decreased slightly in the initial stage with the increase of axial strain, which was caused by the closure of primary cracks. Then, permeability increased slowly with the increase of axial strain due to initiation of new cracks and expansion of original cracks. And then, the permeability increased in magnitude since the main cracks were formed in the elastoplastic stage. Finally, the permeability decreased to be $s$ table due to the compaction of induced fractures. Some experts [16-18] studied the permeability of coal measured rock under cyclic loading and unloading, concluding that the unloading curve of rock did not coincide with the loading curve, forming a closed plastic hysteresis loop, and also obtained the evolution of residual strain with the cyclic times and the damage evolution of coal measured rock. Besides, the relation between confining pressure and permeability was researched [19-26]. The experiments and numerical results indicated that the relationship of confining pressure and coal permeability could be described by an exponential function. In all, most of the studies of coal permeability were conducted on an intact coal specimen since the flow characteristics are more regular and the experimental methods are relatively simple.

Based on the above, the permeability of coal is determined by its deformation and stress state. However, the following aspects are not considered in the previous studies. (1) At present, most of the testing methods are to increase

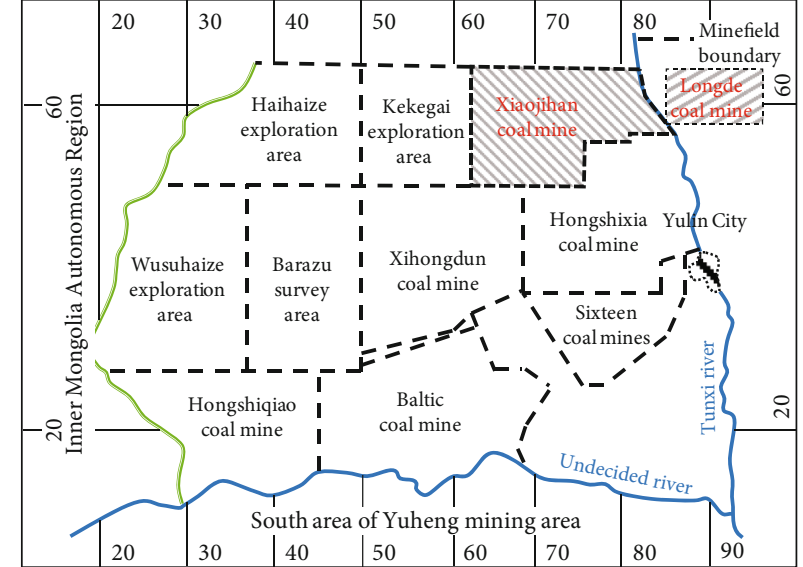

FIgURE 1: Minefield distribution map of the Yulin mining area.

the axial strain or stress gradually under constant confining pressure, which is a simple loading mode since the influence of different stress states on coal permeability and the irrecoverability of deformation is not considered. (2) It is assumed that a specific strain/stress state corresponds to a specific permeability; that is, the permeability of a rock specimen has a fixed expression, without considering the effect of plastic flow. According to Reference [27], elastoplastic behavior has a significant influence on the permeability of coal, especially on the coal with massive water content and fractures. Furthermore, the research of the plastic flow of coal in the main aquifer of a coal seam is seldom reported. (3) For the analysis of the coal seam as the main aquifer, scholars [28, 29] mainly focus on the geological environment of coal seam and the comparison of its strength and permeability with those of upper and lower strata. However, the comparison of mechanical properties and permeability between regular coal seam and main aquifer coal seam is not well understood under the same geological environment.

In this work, the permeability tests are conducted on the Xiaojihan water-bearing coal seam and Longde nonwater coal seam with different cyclic loading and unloading under plastic flow. Then, the reason of water storage in an aquifer coal seam is analyzed through the comparison of permeability between the aquifer coal seam and the nonaquifer coal seam. The study of permeability evolution of the aquifer coal seam under plastic flow is of great significance to the study of the mining stress field, mining fracture field, and water seepage field, as well as the study of the seepage instability behavior of a waterbearing coal seam and prevention of water inrush disaster.

\section{Materials and Testing Method}

2.1. Area of Research. Yuheng Mining Area is located in the border area between Maowusu Desert and Loess Plateau, which is a typical arid and water-deficient area. The water content of coal seams in mining areas of Hongshixia, Xihongdun, Boluo, Yuandatan, Kekegai, Dahaize, Shiliutai, Wusuhaize, Hongshiqiao, and Longde is extremely low (Figure 1). In the early 21 st century, the special geological structure of a coal seam as the main aquifer was first found in the Xiaojihan coal mine of the Yuheng Mining Area, which 


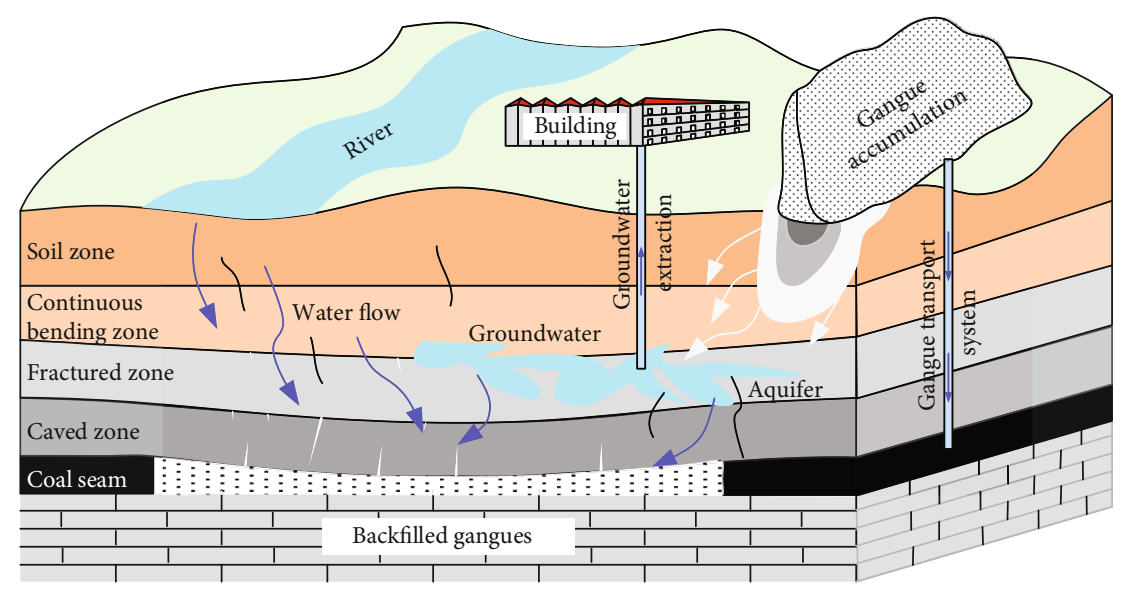

Figure 2: Coal seam groundwater runoff roadmap.
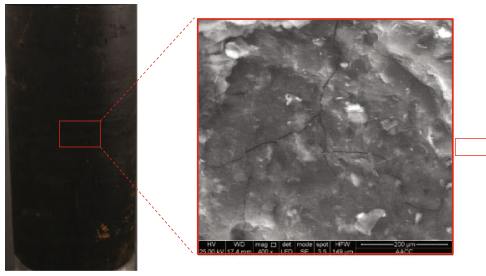

(a) Specimens in Xiaojihan coal mine
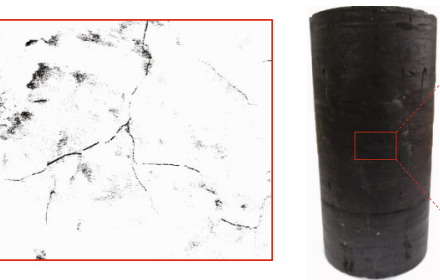

Figure 3: Initial microstructure of specimens. is rare even in south China. Therefore, "the study of the cause of coal seam becoming the main aquifer" has become a hot research topic in the field of coal science and technology.

The coal seam of the Xiaojihan coal mine in Yanheng Mining Area is an aquifer. The water seepage source during the tunneling process of the coal seam roadway is mainly the No. 2 coal seam fissure water and the coal roof sandstone fissure water. Field observations and studies have shown that the No. 2 coal seam is stable in layer structure and simple in structure, but the coal seam fissures are developed, and the direct bottom plate has a certain thickness of the aquifuge, which has a good water storage space [5]. The Xiaojihan No. 2 coal seam is the main aquifer due to its roof rock of water-rich characteristics. The Quaternary unconsolidated groundwater is mainly supplied by precipitation and lateral recharge, partly by desert condensate recharge, irrigation return water, and canal water leakage recharge. Fractured diving in the bedrock weathering zone is recharged directly by atmospheric precipitation infiltration in the exposed area, while the rest is recharged by infiltration of overlying unconsolidated layer diving. The recharge of deep confined water mainly comes from the infiltration of the overlying aquifer, and the overflow channel is mainly the tortuous path of fracture in the aquifer. Thus, adequate source and recharge of fissure water provide favorable conditions for the formation of the main aquifer in a coal seam. The coal seam groundwater runoff roadmap is shown in Figure 2.

2.1.1. Materials. The experiments are intending to study the variation of the permeability of coal pillars with coal seams as the main aquifer under plastic flow. The specimens are from the Xiaojihan water-bearing coal seam and adjacent mining area Longde no-water coal seam with a size of 50 $\mathrm{mm} \times 100 \mathrm{~mm}$. By measuring the wave velocity of coal samples, a more uniform coal sample is screened out. In order to study the basic properties of coal related to its permeability, such as initial fracture characteristics and initial porosity, scanning electron microscopy (SEM) tests and mercury intrusion tests are conducted on coal specimens.

A scanning electron microscope Quanta 250 is used in the SEM tests. The scanning image of the coal specimen is obtained with a magnification of $400 x$. Then, the optimal threshold of the image is determined by selecting the threshold algorithm using a self-developed program. Finally, the fractures in coal specimens are obtained through binary processing of the SEM image as shown in Figure 3.

It can be seen from Figure 3 that a large number of fissures are observed in the Xiaojihan coal sample, and the fissures are curved and have no obvious trend. Moreover, there are many cracks, and the coal structure is loose. Meanwhile, less cracks are found in the Longde coal mine, and the cracks are rarely staggered, and the opening of the fissures is basically unchanged.

An Autopore 9500 mercury porosimeter is used in mercury intrusion tests, and the experimental results of Xiaojihan coal specimens and Longde coal specimens are shown in Table 1.

In order to compare the initial pore structure of these two different coal specimens directly, Figure 4 is drawn correspondingly.

As shown in Table 1 and Figure 4, the initial porosity and permeability of the water-bearing coal seam are $9.89 \%$ and 
TABLE 1: The experiment results of mercury intrusion tests.

\begin{tabular}{lcccccc}
\hline Specimens & No. & $\begin{array}{c}\text { C1 } \\
\text { Porosity (\%) }\end{array}$ & $\begin{array}{c}\text { Total amount of mercury }(\mathrm{ml} / \mathrm{g}) \\
\text { Termeability }\left(\mathrm{m}^{2}\right)\end{array}$ & $\begin{array}{c}\text { C4 } \\
\text { Total pore area }\left(\mathrm{m}^{2} / \mathrm{g}\right)\end{array}$ & $\begin{array}{c}\mathrm{C} 5 \\
\text { Average pore size }(\mathrm{nm})\end{array}$ \\
\hline Xiaojihan & M1 & 9.89 & 0.0892 & $8.51 \times 10^{-15}$ & 44.95 & 7.91 \\
Longde & M2 & 8.97 & 0.0796 & $4.54 \times 10^{-15}$ & 41.14 & 7.70 \\
\hline
\end{tabular}

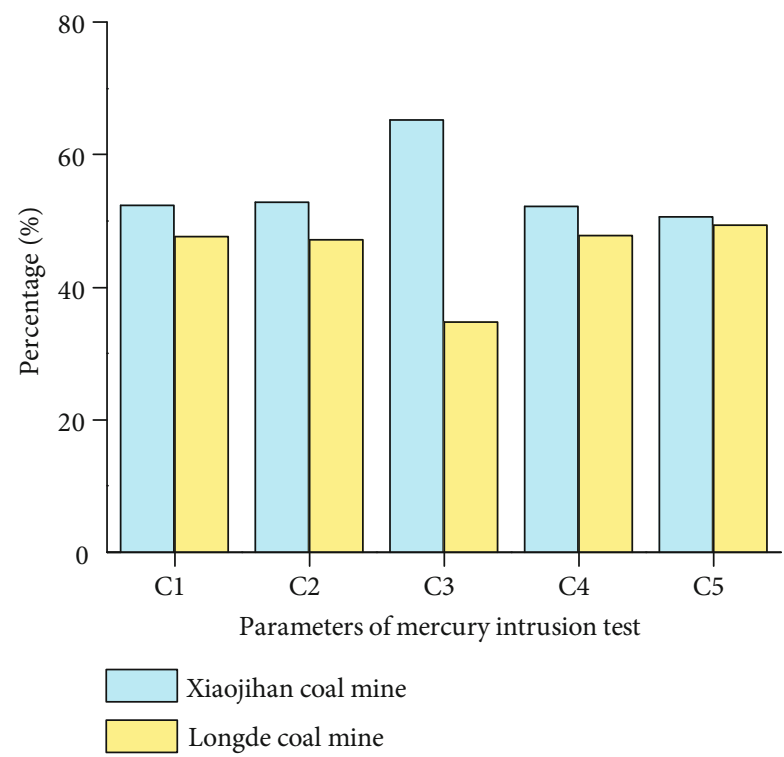

Figure 4: The experiment results of mercury intrusion tests of the water-bearing coal seam and no-water coal seam. Note: (a) C1, C2, C3, C4, and C5 denote porosity, total amount of mercury, permeability, total pore area, and average pore size, respectively. (b) The ordinate indicates the proportion of the two coal seams under the same parameter.

$8.51 \times 10^{-15} \mathrm{~m}^{2}$, respectively. The initial porosity, total mercury amount, initial permeability, total pore area, and average pore size of Xiaojihan coal specimens are all greater than those of Longde coal specimens, indicating that the water storage capacity of the Xiaojihan coal seam is stronger than that of the Longde coal seam.

2.2. Testing Method. The methods of conventional triaxial tests and permeation tests under plastic flow are introduced based on the test principle and equipment.

2.2.1. Testing System. The schematic diagram of the penetration test system is shown in Figure 5. The penetration test system is composed of an axial loading system (MTS816), confining pressure system (oil pump), permeation loop (hydraulic pump), and permeation meter (self-made cylinder). Its main functions included the following: (a) applying axial load to the rock sample through the MTS816 rock mechanic control system; (b) applying confining pressure to the rock sample through the oil pump; besides, $\mathrm{A}$ is the inlet end of the oil; and (c) applying pore pressure (osmotic pressure) to the upper and lower end faces of the rock sample. $\mathrm{B}$ and $\mathrm{C}$ are the inlet ends of the bottom water and top water, respectively. The permeation circuit consists of a per-

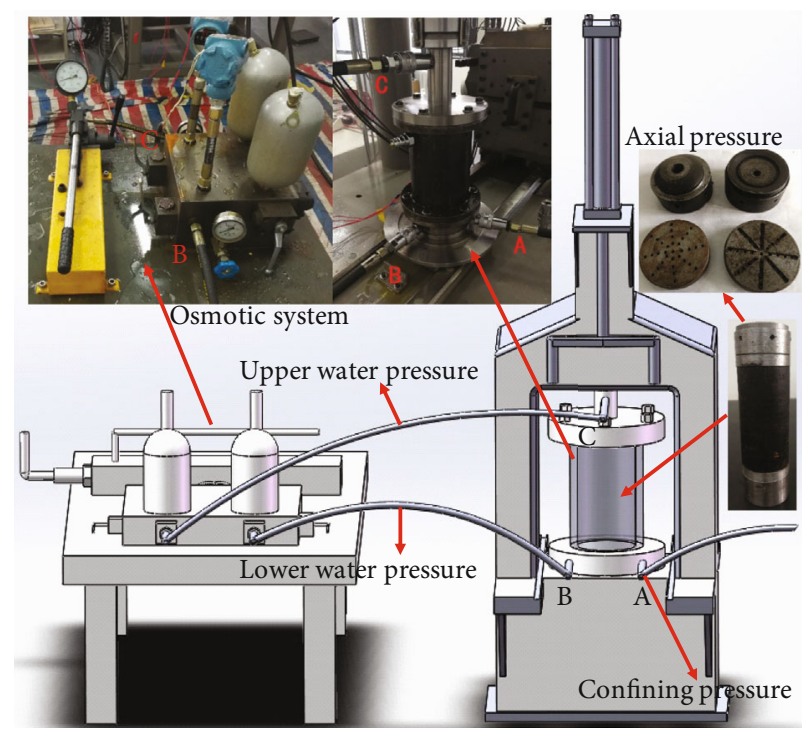

Figure 5: The schematic diagram of the penetration test system.

meameter, a manual pump, a pressure sensor, a paperless recorder, a pressure gauge, and a storage tank.

A standard cylindrical coal sample is placed in the cylinder. The porous disk is arranged above and below the coal sample as shown in Figure 5. The role of the porous disk is to distribute fluid pressure and equalize the percolation velocity. The upper steel plate is designed as a spherical surface to match the convex upper surface of the contact. These two parts can be rotated relative to each other to adjust the parallelism between the coal sample, the porous disk, the steel plate, and the piston. The design above avoids eccentric loads.

In order to study the mechanism of coal permeability evolution under plastic flow, it is necessary to measure the radial residual strain. And a bow sensor is introduced, which is connected to a static strain guage at the central hole of the pin shaft as shown in Figure 6. The data acquisition system consists of a static resistance strain indicator, a pressure sensor, a paperless recorder, and a notebook computer. The system can collect radial strain and pore pressure values in real time.

2.2.2. Experiment Scheme. In order to simulate the evolution of coal seam deformation and water seepage caused by unloading of underground roadway excavation and the evolution of permeability versus confining pressure of coal specimens from the main aquifer coal seam under plastic flow, the conventional triaxial tests are conducted to make the coal specimens reach the state of plastic zone; then, the confining pressure is loaded and unloaded to measure the permeability during the process. The specific procedures are as follows: 


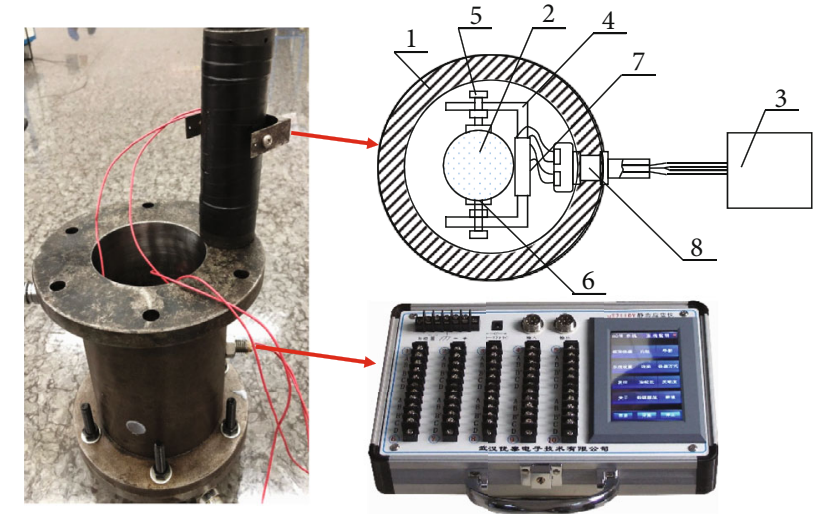

Figure 6: The bow sensor and static strain gauge. Note: 1: cylinder as a three-axis chamber; 2: coal sample; 3: static resistance strain gauge; 4: radial displacement sensor bracket; 5 : fastening bolt; 6 : clamping piece; 7: strain gauges; 8 : hinge pin.

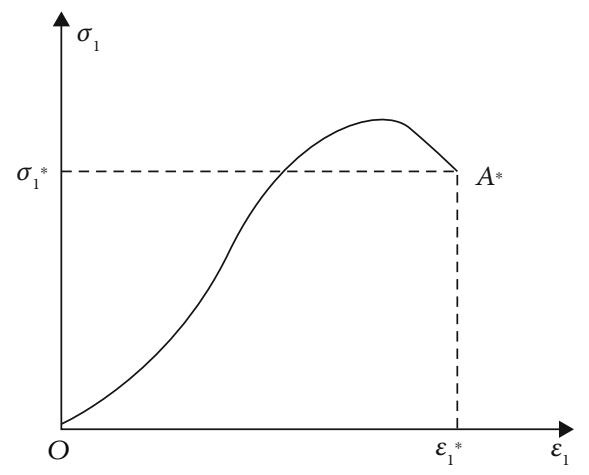

FIgURE 7: The stress-strain curve of coal in the postpeak stage.

(a) The confining pressure of $2 \mathrm{MPa}$ is applied to coal specimens at a loading rate of $0.5 \mathrm{MPa} / \mathrm{s}$; then, the specimen is loaded in the axial direction to postpeak stress state $A^{*}$ with a loading rate of $0.003 \mathrm{~mm} / \mathrm{s}$ $\left(\sigma_{1}{ }^{*}=90 \% \sigma_{\max }\right)$. And the axial strain is $\varepsilon_{1}{ }^{*}$ at this state and remains constant (Figure 7). If the pressure of the hysteresis' starting point, which means $\sigma_{1}{ }^{*}$, closes to the peak, the pressure's hysteresis would be more plump and the change of permeability of rock samples under plastic flow would be much more comprehensive. The change of permeability under plastic flow can be reflected much more comprehensively. TestStar controls axial pressure of state $A^{*}$ under 90 percent of peak pressure, which is MTS816 experiment systems' software. However, if exceeding $90 \%$, it may lead to out of control, and the coal sample would be crushed. Because of the large discreteness of coal, it is not easy to determine the state of each coal sample reaching the plastic zone. Therefore, $90 \%$ of the peak stress of each coal sample in the postpeak stage is taken as the initial value of the plastic zone

(b) Xiaojihan coal seam buried depth is $350 \mathrm{~m}$ [30], its covered rock formation's average density is $2600 \mathrm{~kg} / \mathrm{m}^{3}$, and vertical ground stress is $8.92 \mathrm{MPa}$.

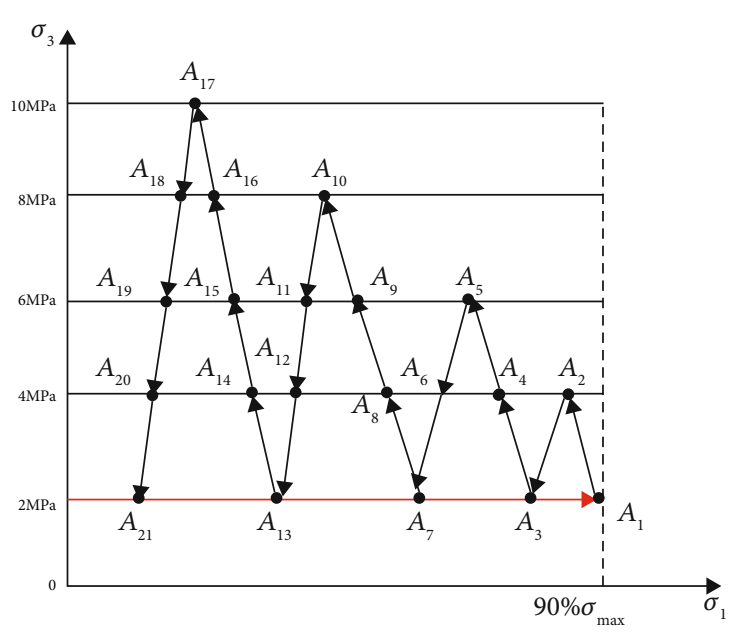

FIGURE 8: Penetration tests with different confining pressure loading and unloading cycles.

According to the definition of the pressure coefficient [31], lateral pressure vector is 1.11 , so we obtain horizontal ground stress $9.81 \mathrm{MPa}$ and the pore pressure difference $1.5 \mathrm{MPa}$, so the minimum confining pressure is selected to be $2 \mathrm{MPa}$, and the fixed confining pressure is selected to be $2 \mathrm{MPa}, 4 \mathrm{MPa}, 6 \mathrm{MPa}$, $8 \mathrm{MPa}$, and $10 \mathrm{MPa}$

(c) Based on what is mentioned above, permeabilty tests with different confining pressure loading and unloading cycles are schemed as follows:

$$
\begin{aligned}
& \text { (1) } 2 \mathrm{MPa}\left(A_{1}\right) \longrightarrow 4 \mathrm{MPa}\left(A_{2}\right) \longrightarrow 2 \mathrm{MPa}\left(A_{3}\right) \\
& (2) 2 \mathrm{MPa}\left(A_{3}\right) \longrightarrow 4 \mathrm{MPa}\left(A_{4}\right) \underset{\mathrm{MPa}}{\longrightarrow}\left(A_{5}\right) \\
& \longrightarrow 4 \mathrm{MPa}\left(A_{6}\right) \longrightarrow 2 \mathrm{MPa}\left(A_{7}\right)
\end{aligned}
$$

(3) $2 \mathrm{MPa}\left(A_{7}\right) \longrightarrow 4 \mathrm{MPa}\left(A_{8}\right) \longrightarrow 6 \mathrm{MPa}\left(A_{9}\right) \longrightarrow$ $8 \mathrm{MPa}\left(A_{10}\right) \longrightarrow 6 \mathrm{MPa}\left(A_{11}\right) \longrightarrow 4 \mathrm{MPa}\left(A_{12}\right)$ $\longrightarrow 2 \mathrm{MPa}\left(A_{13}\right)$

(4) $2 \mathrm{MPa}\left(A_{13}\right) \longrightarrow 4 \mathrm{MPa}\left(A_{14}\right) \longrightarrow 6 \mathrm{MPa}\left(A_{15}\right)$ $\longrightarrow 8 \mathrm{MPa}\left(A_{16}\right) \longrightarrow 10 \mathrm{MPa}\left(A_{17}\right) \longrightarrow 8 \mathrm{MPa}$ $\left(A_{18}\right) \longrightarrow 6 \mathrm{MPa}\left(A_{19}\right) \longrightarrow 4 \mathrm{MPa}\left(A_{20}\right) \longrightarrow 2$ $\operatorname{MPa}\left(A_{21}\right)$

Penetration tests were carried out separately at the above 21 stress state points (Figure 8). Axial strain $\varepsilon_{1}^{*}$ is divided into five grades, and plastic zone state $\varepsilon_{1}^{*}$ is determined according to the actual situation. The initial confining pressure of each water-bearing specimen is $2 \mathrm{MPa}$. In order to compare the permeability of two kinds of coal specimens under the same stress state, if the strain $\varepsilon_{1}^{*}$ of the nonaquifer coal sample is different from that of the aquifer coal sample, the axial strain is applied to make it reach the same level $\left(\varepsilon_{1}^{*}\right)$. Pore pressure difference at upper and lower ends of the permeability test under each confining pressure is $1.5 \mathrm{MPa}(\triangle P=1.5 \mathrm{MPa})$ as shown in Table 2.

2.2.3. Experiment Principle. Due to the low permeability of coal [32], $90 \%$ of peak stress of the coal specimen in the 
TABLE 2: Pore pressure at upper and lower ends.

\begin{tabular}{|c|c|c|}
\hline \multirow{2}{*}{$\begin{array}{l}\text { Confining pressure } \\
(\mathrm{MPa})\end{array}$} & \multicolumn{2}{|c|}{ Hydraulic pressure } \\
\hline & $\begin{array}{c}\text { Upper pore } \\
\text { pressure (MPa) }\end{array}$ & $\begin{array}{c}\text { Lower pore } \\
\text { pressure }(\mathrm{MPa})\end{array}$ \\
\hline 2 & 1.7 & 0.2 \\
\hline 4 & 3.5 & 2.0 \\
\hline 6 & 5.5 & 4.0 \\
\hline 8 & 7.5 & 6.0 \\
\hline 10 & 9.5 & 8.0 \\
\hline
\end{tabular}

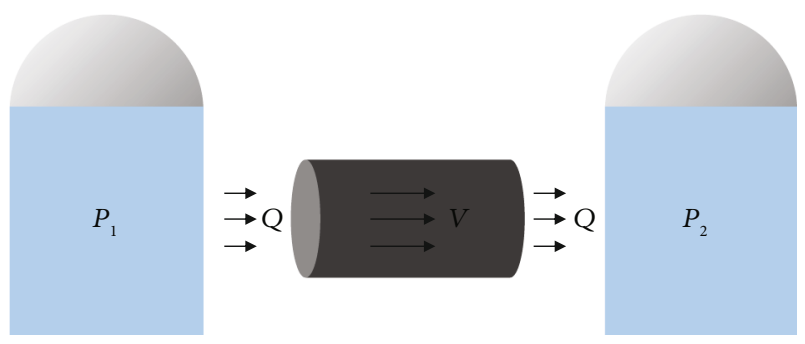

Figure 9: Principle of the transient method.

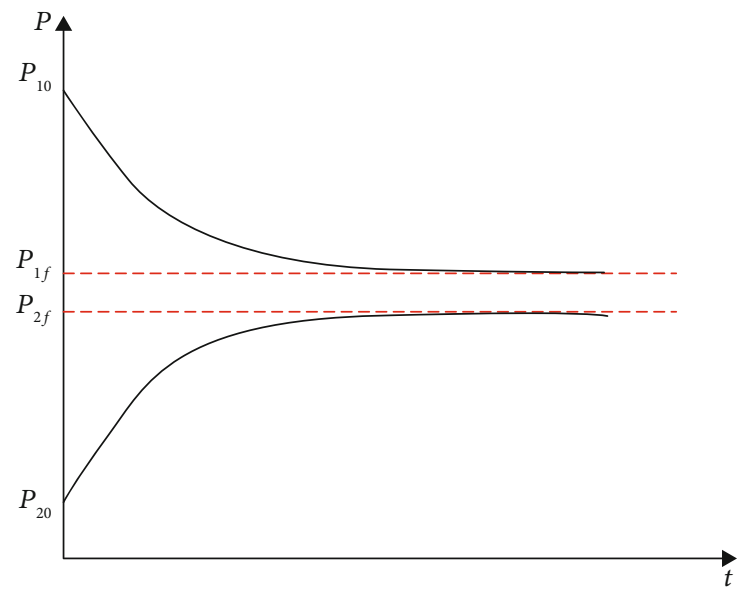

FIgURE 10: Pressure change curves for the water tanks.

postpeak stage is taken as the initial value of the plastic zone. Although macrocracks could be observed in the coal specimen, the seepage velocity is still at a low level, and water could not be collected at the outlet. Therefore, the transient method is applied to determine the permeability of the coal specimen, and the principle of this method is shown in Figure 9.

The height and cross-sectional area of the coal specimens are $H$ and $A$, respectively. At the beginning of the experiment, the initial pressures at the two ends of the coal specimen are $P_{10}$ and $P_{20}\left(P_{10}>P_{20}\right)$. The axial pressure gradient in the coal specimen is $\left(P_{20}-P_{10}\right) / H$. During the process of infiltration, the liquid in tank 1 moves to tank 2 by passing through the coal specimen. As a result, the pressure of tank 1 continuously decreases, while that of tank 2 continuously increases, and the pressure gradient gradually decreases until the pressures of two tanks reach an equilibrium state (see Figure 10). We assume that the mass flow rate of the liquid entering the coal specimen from tank 1 is $q$. If the coal specimen is water-saturated, the mass flow rate of the liquid entering water tank 2 from the coal specimen is $q$ . The seepage velocity in the rock sample is $V=q / \rho A$. Water is considered as compressible, and its compression factor is defined as follows:

$$
\frac{1}{c_{f}}=\frac{\rho d P_{1}}{d \rho},
$$

where $c_{f}$ is the compressibility of water and $\rho$ is the density of water. Equations (2) and (3) can be derived from $d \rho=-q d t / B$ and $q=\rho A V$ :

$$
\begin{aligned}
& \frac{d P_{1}}{d t}=-\frac{A V}{c_{f} B}, \\
& \frac{d P_{2}}{d t}=-\frac{A V}{c_{f} B} .
\end{aligned}
$$

Equation (4) can be induced from equations (2) and (3):

$$
V=\frac{\left(c_{f} B\right) d\left(P_{1}-P_{2}\right)}{2 A d t}
$$

According to Darcy's law, the seepage velocity is defined as

$$
V=\frac{-k\left(P_{2}-P_{1}\right)}{\mu H} .
$$

Substituting equation (5) into (4), the following equation can be obtained:

$$
\frac{d\left(P_{1}-P_{2}\right)}{P_{1}-P_{2}}=\frac{-2 A k d t}{c_{f} B H \mu} .
$$

During the test, pressure data are collected at equal intervals $\tau$, with a total of $n$ acquisitions. At the end of data collection, the pressures in the water tanks at $t_{f}=n$ $\pi$ are $P_{1 f}$ and $P_{2 f}$, respectively. The integral of equation (6) is obtained:

$$
k=\frac{c_{f} B H \mu\left[\ln \left(P_{10}-P_{20}\right)-\ln \left(P_{1 f}-P_{2 f}\right)\right]}{2 t_{f} A} .
$$

A typical confining pressure-permeability hysteresis curve is shown in Figure 11. In order to describe the influence of axial strain on the confining pressure-permeability hysteresis curve, two parameters named confining pressure influence coefficient and permeability recovery coefficient are introduced here. And the confining pressure influence coefficient is defined in

$$
Y_{1}^{(\mathrm{i})}=10^{14} \cdot \frac{\mathrm{k}_{\mathrm{b}}^{(\mathrm{i})}-\mathrm{k}_{\mathrm{r}}^{(\mathrm{i})}}{\sigma_{3}^{(\mathrm{i})}-\sigma_{3}^{\mathrm{b}}}, \quad \mathrm{i}=1,2,3,4,
$$




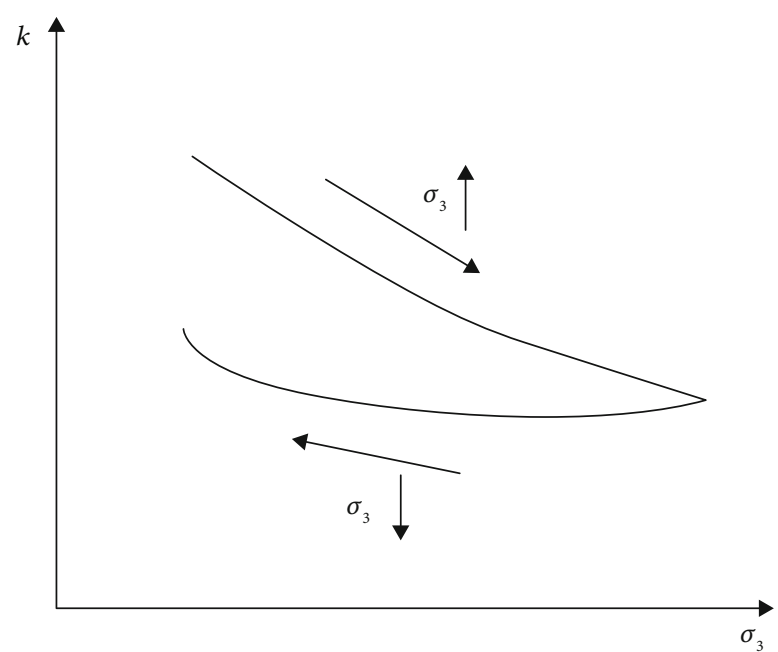

FIgURE 11: The confining pressure-permeability curve.

where $\sigma_{3}^{(i)}$ and $k_{b}^{(i)}$ are the confining pressure and permeability at the beginning of cycle times $i$ and $\sigma_{3}^{(i)}$ and $k_{r}^{(i)}$ are the confining pressure and permeability of reverse point $(2 i-1)$, respectively.

The permeability recovery coefficient is defined as

$$
r_{2}^{(i)}=\frac{k_{e}^{(i)}}{k_{b}^{(i)}}, \quad i=1,2,3,4,
$$

where $k_{e}^{(i)}$ is the permeability at the end of cycle times $i, i=$ $1,2,3,4$.

\section{Results and Discussion}

In this section, the coal sample is first brought to the state of the plastic zone by a conventional triaxial compression test. Secondly, the hysteresis curve of permeability is obtained by the permeability test under plastic flow, and the variation law of permeability is analyzed.

3.1. Results of Conventional Triaxial Compression Tests. A conventional triaxial compression test was carried out on the coal sample to make it reach the state of the plastic zone. The confining pressure is kept as $2 \mathrm{MPa}$. The stress-strain curves of two kinds of coal specimens are shown in Figure 12, and the damage load, peak stress, and peak strain are shown in Table 3.

In order to obtain the same $\varepsilon_{1}{ }^{*}$ with the water-bearing coal specimen, the non-water-bearing coal specimen is in the plastic zone state of $70 \%-90 \%$ peak stress by controlling the MTS816 program. If $\varepsilon_{1}{ }^{*}$ of the non-water-bearing coal specimen is in a large difference with that of the waterbearing coal specimen, the non-water-bearing coal specimen is regarded as unqualified. The results are shown in Table 4.

\subsection{Variation of Relative Residual Strain under Plastic Flow.} The evolution of permeability is closely related to the deformation of coal specimens. In order to study the mechanism of permeability evolution, plastic flow tests are conducted on water-bearing coal specimens under constant strains of $1.61 \%, 1.72 \%, 1.79 \%, 1.81 \%$, and $2.01 \%$, respectively. The hysteretic curves of circumferential strain-circumferential stress (confining pressure) are shown in Figure 13.

It can be seen from Figure 13 that the hysteresis curve of radial strain-radial stress of the coal sample under constant axial strain has the following characteristics. When confining pressure is unloaded to the initial value at each stage of axial strain, the circumferential strain lags behind the circumferential stress, and the circumferential strain could not return to the initial value, resulting in irreversible deformation. Therefore, the loading-unloading curve of circumferential strain-circumferential stress does not form a closed hysteresis loop.

Relative residual strain is introduced to describe the plastic deformation [33]. The transverse strain corresponding to the lower limit circumferential stress point of each cycle in the circumferential strain-circumferential stress hysteresis curve is extracted, and the relative residual strain of the cycle times $i$ is calculated according to

$$
\Delta \varepsilon_{3 \mathrm{i}}=\varepsilon_{3 \mathrm{i}}-\varepsilon_{3 \mathrm{i}-1},
$$

where $\Delta \varepsilon_{3 \mathrm{i}}$ is the relative residual transverse strain at cycle times $i$ and $\varepsilon_{3 \mathrm{i}}$ is the residual transverse strain at cycle times $i$. The relative residual transverse strain of each cycle under each stage of axial strain is shown in Table 5 .

The increase of the cyclic coefficient corresponds to the increase of confining pressure. In order to observe the influence of axial strain and confining pressure on relative residual strain, the relative residual strain versus confining pressure under different strain states is drawn according to Table 5 (see Figure 14).

The following is concluded from Table 5 and Figure 14. (a) The relative residual strain is relatively large at the initial increase of confining pressure under the same axial strain. The relative residual strain decreases slowly with the increase of confining pressure, which indicates that plastic deformation is produced mainly in the first cyclic loading and unloading with the increase of confining pressure, resulting in a large irrecoverable deformation. And the coal specimens are mainly under a neutral load during the last three loading and unloading cycles; that is to say, the elastic deformation of the coal specimens is produced after plastic deformation. (b) The relative residual strain increases with the increase of axial strain under the same confining pressure, which shows the irrecoverable deformation and plasticity increase with the increase of axial strain.

3.3. The Permeability versus Confining Pressure and Axial Strain under Plastic Flow. Plastic flow permeation tests of two kinds of coal specimens under different constant strains are conducted, and the number of loading and unloading cycles was four. The experiment results are shown in Figures 15-19, and permeability of water-bearing and non-water-bearing coal specimens from the beginning of each cycle to the reverse point of each cycle is shown in Tables 6-10. 


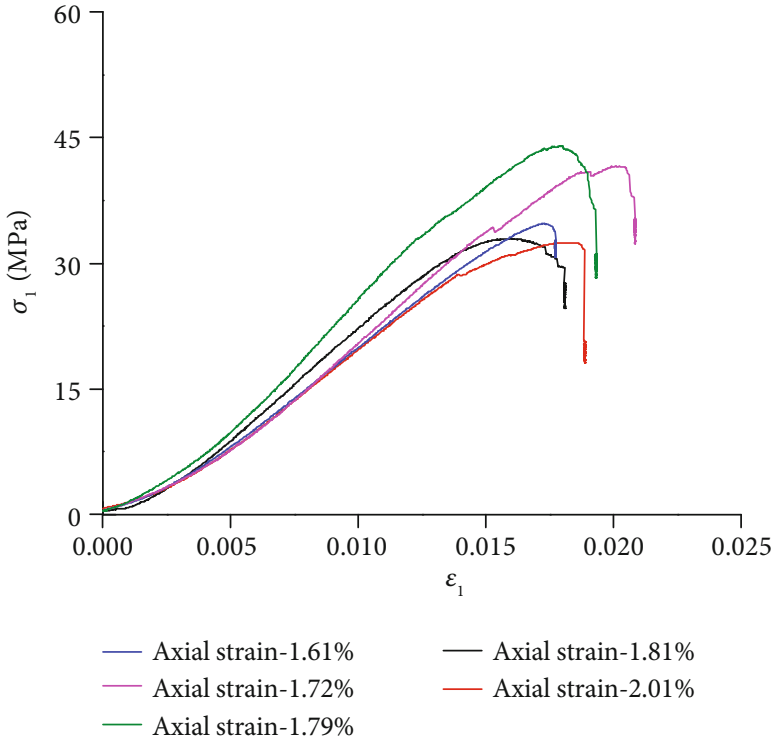

(a) Xiaojihan coal mine

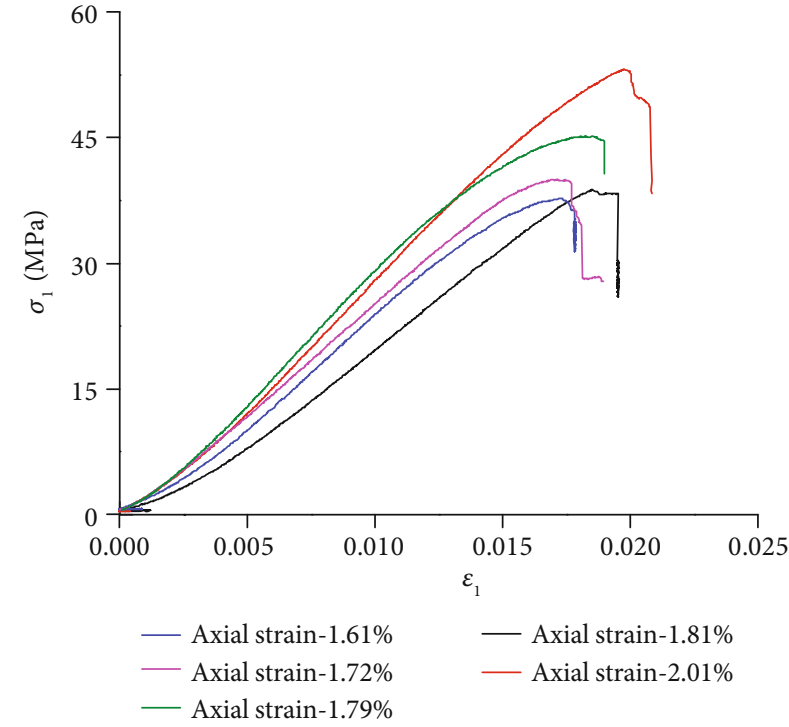

(b) Longde coal mine

Figure 12: The stress-strain curves of two kinds of specimens under confining pressure of $2 \mathrm{MPa}$.

TABLE 3: The damage load, peak stress, and peak strain of water-bearing specimens under confining pressure of $2 \mathrm{MPa}$.

\begin{tabular}{|c|c|c|c|c|c|c|}
\hline Specimen no. & Diameter $(\mathrm{mm})$ & Height (mm) & Damage load $(\mathrm{kN})$ & Peak stress (MPa) & $\sigma_{\mathrm{A}}^{*}(\mathrm{MPa})$ & $\varepsilon_{1}^{*}\left(10^{-2}\right)$ \\
\hline $\mathrm{X}-21$ & 50.2 & 99.8 & 65.20 & 32.96 & 29.66 & 1.61 \\
\hline $\mathrm{X}-22$ & 50.0 & 99.9 & 67.89 & 34.73 & 31.26 & 1.72 \\
\hline $\mathrm{X}-23$ & 49.9 & 100.0 & 63.72 & 32.47 & 29.22 & 1.79 \\
\hline $\mathrm{X}-24$ & 50.3 & 100.9 & 86.94 & 43.95 & 39.56 & 1.81 \\
\hline $\mathrm{X}-25$ & 50.2 & 100.3 & 82.60 & 41.59 & 37.43 & 2.01 \\
\hline
\end{tabular}

TABLE 4: The damage load, peak stress, and peak strain of specimens without water under confining pressure of $2 \mathrm{MPa}$.

\begin{tabular}{lcccccc}
\hline Specimen no. & Diameter $(\mathrm{mm})$ & Height $(\mathrm{mm})$ & Damage load $(\mathrm{kN})$ & Peak stress $(\mathrm{MPa})$ & $\sigma_{\mathrm{A}}^{*}(\mathrm{MPa})$ & $\varepsilon_{1}^{*}\left(10^{-2}\right)$ \\
\hline L-21 & 49.9 & 99.9 & 74.22 & 37.18 & $32.34(87 \%)$ & 1.61 \\
L-22 & 50.0 & 100.1 & 78.59 & 40.05 & $33.84(85 \%)$ & 1.72 \\
L-23 & 50.1 & 100.2 & 88.84 & 45.20 & $38.42(85 \%)$ & 1.79 \\
L-24 & 49.9 & 100.2 & 76.28 & 38.87 & $34.98(90 \%)$ & 1.81 \\
L-25 & 49.8 & 99.6 & 104.46 & 53.23 & $47.89(89 \%)$ \\
\hline
\end{tabular}

In order to study the influence of axial strain and confining pressure on permeability under plastic flow, the confining pressure influence coefficient and permeability recovery coefficient of water-bearing and non-water-bearing coal specimens under different axial strains are obtained as shown in Tables 11-14.

3.3.1. The Evolution of Permeability versus Confining Pressure. As shown in Figures 15-19, the permeability of the coal specimen decreases exponentially with the increase of confining pressure under the same axial strain, which is in good agreement with previous studies [18-20]. At the initial stage of confining pressure loading, the permeability of water-bearing coal decreases rapidly. Then, the decrease of permeability becomes slower with the increase of confining pressure. According to the pore fracture theory of coal rock mass [34], water flow passage in coal measured media contains pores and cracks. Since the stress surface of the pore is arch and the stress is compressive, the deformation of pore volume is relatively small. While coal crack lacks the support of a skeleton matrix, its deformation is relatively large under compression. Therefore, the main sequence of the deformation of the fluid passage caused by the increase of the confining pressure is the following: the deformation of the fracture under pressure and the closure $\longrightarrow$ the deformation of the partial pores. During the whole process, the compression deformation and closure of coal cracks and pores become more and more difficult, resulting in the stability of permeability with the increase of confining pressure.

As shown in Tables 11 and 12, permeability of waterbearing coal specimens is particularly large at the low confining pressure stage. Since most of the cracks and microchannels 


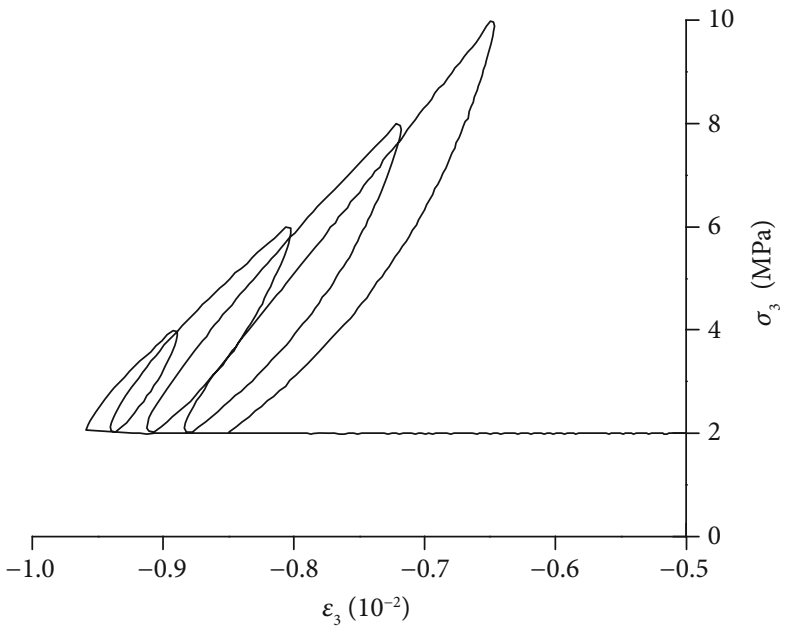

(a) The axial strain was $1.61 \%$

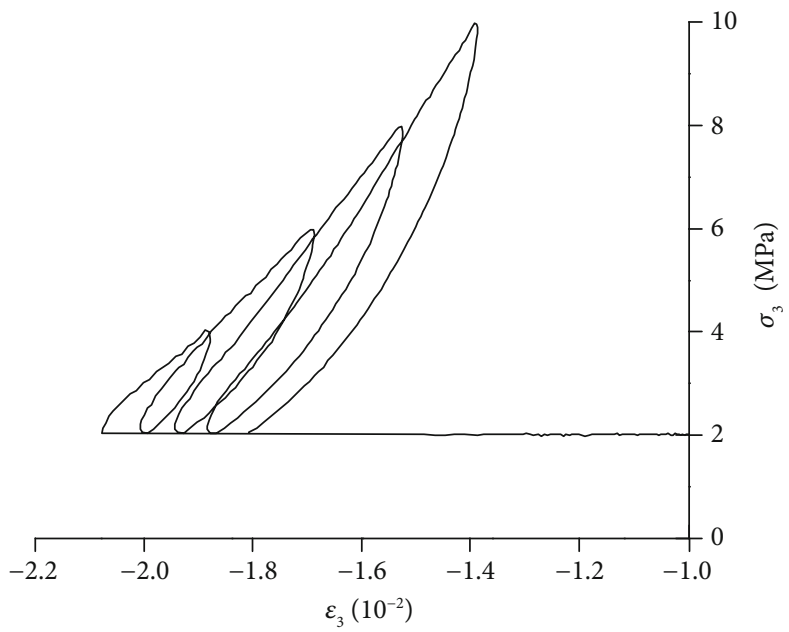

(c) The axial strain was $1.79 \%$

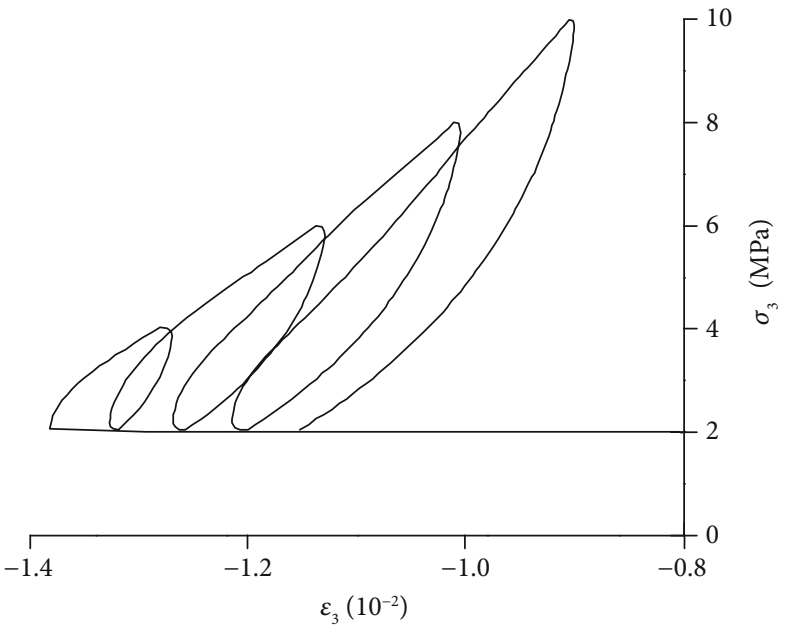

(b) The axial strain was $1.72 \%$

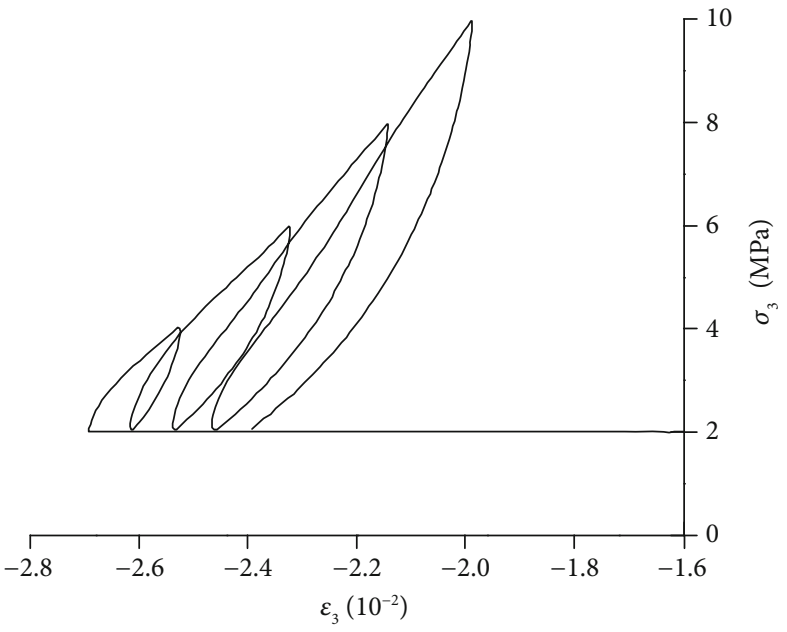

(d) The axial strain was $1.81 \%$

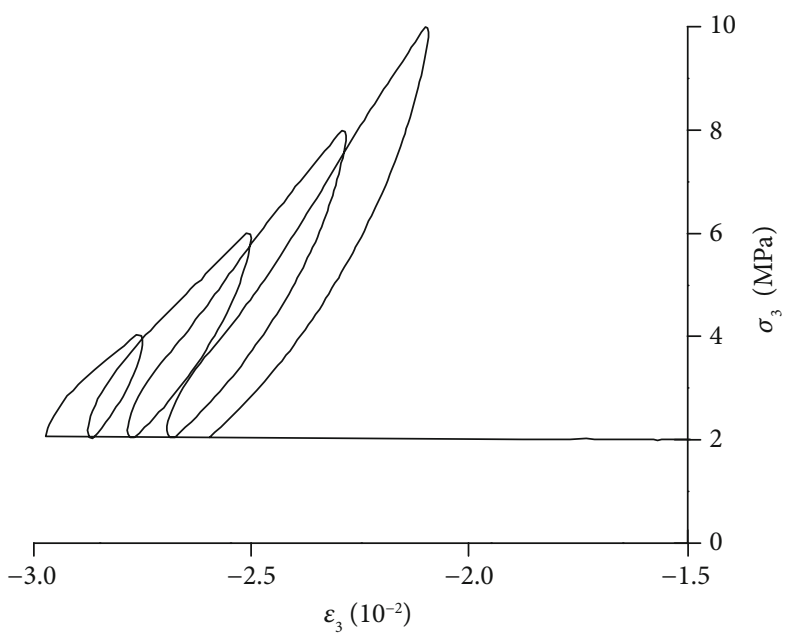

(e) The axial strain was $2.01 \%$

FIGURE 13: The circumferential strain-circumferential stress curve of water-bearing coal specimens under constant axial strain.

are closed after the plastic deformation of the coal specimen due to confining pressure loading, a few of microcracks that are compressible remained. Only large pore volume could be compressed, and compressive deformation is formed, resulting in the change of permeability. Therefore, the influence of confining pressure on permeability of the second 
TABLE 5: The relative residual strain of $\varepsilon_{3}-\sigma_{3}$ curve under different axial strains.

\begin{tabular}{lcccc}
\hline \multirow{2}{*}{ Axial strain (\%) } & \multicolumn{4}{c}{ Cycle times } \\
& 1 & 2 & 3 & 4 \\
\hline $\mathrm{X}-1.61$ & $3.31 E-4$ & $2.84 E-4$ & $2.41 E-4$ & $2.27 E-4$ \\
$\mathrm{X}-1.72$ & $6.31 E-4$ & $5.73 E-4$ & $5.47 E-4$ & $5.22 E-4$ \\
$\mathrm{X}-1.79$ & $7.77 E-4$ & $6.57 E-4$ & $6.32 E-4$ & $6.11 E-4$ \\
$\mathrm{X}-1.81$ & $9.1 E-4$ & $7.9 E-4$ & $7.41 E-4$ & $7.11 E-4$ \\
$\mathrm{X}-2.01$ & 0.00108 & $9.5 E-4$ & $9.15 E-4$ & $8.88 E-4$ \\
\hline
\end{tabular}

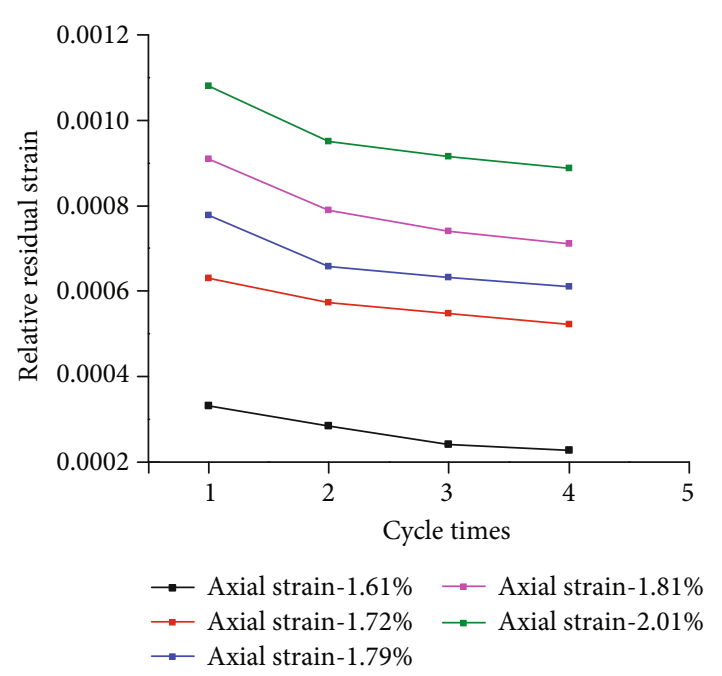

Figure 14: The relative residual strain of $\varepsilon_{3}-\sigma_{3}$ curve under different axial strains.

loading is much weaker than that of the first loading. For coal specimen $\mathrm{X}-2.01 \%$, the permeability decreases from $4.09 \times$ $10^{-15} \mathrm{~m}^{2}$ to $2.76 \times 10^{-15} \mathrm{~m}^{2}$ with the confining pressure increases from $2 \mathrm{MPa}$ to $4 \mathrm{MPa}$, and the permeability reduction rate is $0.067 \mathrm{~m}^{2} / \mathrm{MPa}$. And the permeability reduction rates are $0.067 \mathrm{~m}^{2} / \mathrm{MPa}, 0.023 \mathrm{~m}^{2} / \mathrm{MPa}, 0.012 \mathrm{~m}^{2} / \mathrm{MPa}$, and $0.006 \mathrm{~m}^{2} / \mathrm{MPa}$ with the confining pressure increases from $2 \mathrm{MPa}$ to $4 \mathrm{MPa}, 6 \mathrm{MPa}, 8 \mathrm{MPa}$, and $10 \mathrm{MPa}$, respectively. The results indicate that the permeability reduction rate decreases with the increase of confining pressure.

The relationship between permeability and confining pressure is several-for-one under the same axial strain as shown in Figures 15-19. The permeability of the waterbearing coal specimen in the unloading stage is less than that in the loading stage, which indicates that the irreversible deformation of the coal specimen occurs during the confining pressure loading stage. And there is an obvious stress lag effect in the recovery of permeability of water-bearing coal specimens, which corresponds to the stress-strain lag in the section.

The permeability recovery coefficient grows with the increase of confining pressure as shown in Tables 13 and 14. During four unloading processes, the permeability increases to a certain extent, but it could not recover to the initial value. And the recovery of permeability gets slower with the increase of confining pressure. The permeability loss rates of coal specimens in the last three loading and unloading processes are much smaller than that in the first loading and unloading process. The results show that the waterbearing coal specimens are mainly subjected to neutral loading in the last three loading and unloading processes; that is to say, the elastic deformation after plastic deformation can be restored to a greater extent after unloading. However, the plastic deformation of coal specimens is dominant due to the existence of opening cracks and throats during the first loading and unloading process. For coal specimen X-2.01\%, the permeability of the coal specimen decreases from 2.48 $\times 10^{-14} \mathrm{~m}^{2}$ to $1.98 \times 10^{-14} \mathrm{~m}^{2}$ in the first unloading process, and the permeability recovery coefficient is 0.80 . The permeability recovery coefficients are $0.80,0.84,0.85$, and 0.86 during the four unloading processes, respectively.

3.3.2. The Evolution of Permeability versus Axial Strain. The confining pressure influence coefficient of the waterbearing coal specimen decreases with the increase of axial strain under the same confining pressure shown in Tables 11 and 12. According to Table 5, the plastic deformation becomes greater with the increase of axial strain due to the closure of lots of cracks and pores during this process. Thus, the rest of microcracks and pores not compressed becomes less, decreasing the influence of confining pressure on permeability.

The permeability recovery coefficient of the waterbearing coal specimen decreases with the increase of axial strain under the same confining pressure shown in Tables 13 and 14, indicating that the plastic deformation increases with the growth of axial strain. According to Table 5 and Figure 13, when the coal specimen is compressed more compactly, the irrecoverable deformation of the waterbearing coal specimen becomes greater, resulting in the decrease of the permeability recovery coefficient.

3.3.3. Brief Analysis on the Cause of Water Containing in Xiaojihan Coal Seam. In order to compare the confining pressure influence coefficient and permeability recovery coefficient of two kinds of coal specimens under the same stress level, Figure 20 is drawn according to Tables 11-14.

The confining pressure influence coefficient and permeability recovery coefficient of nonwater coal specimens are greater than those of water-bearing coal specimens under the same stress level, which shows that the permeability of the water-bearing coal specimen is more insensitive to the change of stress. In the process of periodic displacement of the coal seam, the closure rate of internal cracks of the water-bearing coal specimen is lower than that of the nonwater coal specimen, which is beneficial for water storage and transport.

The order of magnitude of permeability of the waterbearing coal seam is greater than that of the nonwater coal seam under the same stress level. Water from roof strata can easily penetrate into the aquifer coal seam, which is the main reason for the coal seam in the Xiaojihan coal mine as the main aquifer.

There are sufficient fissure water source and recharge in the Xiaojihan No. 2 coal seam as stated in Section 2.1. From 


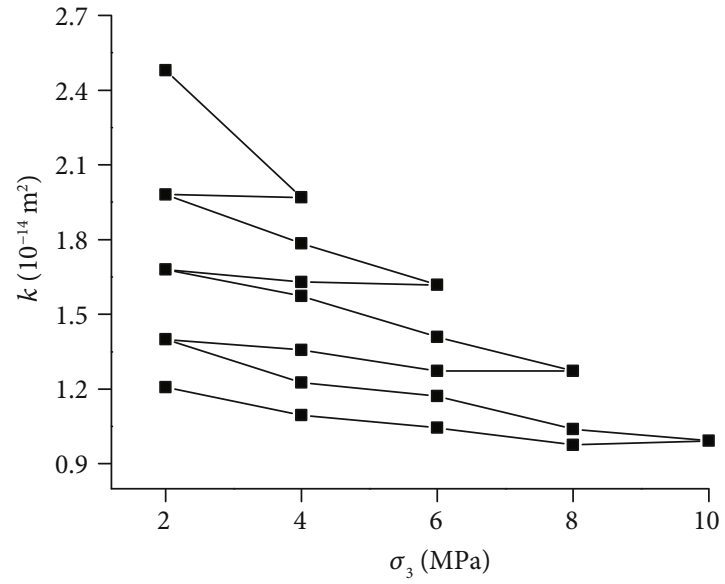

(a) $\mathrm{X}-1.61 \%$

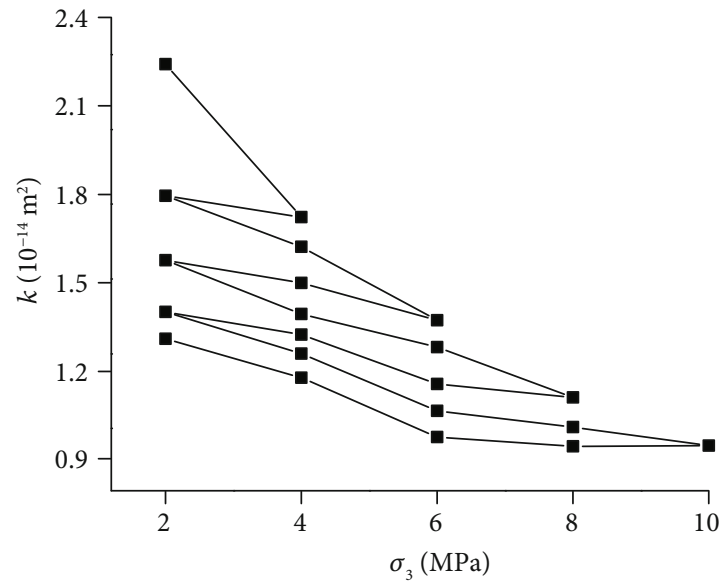

(b) $\mathrm{L}-1.61 \%$

FIGURE 15: The permeability evolution during the loading-unloading process with the axial strain $1.61 \%$.

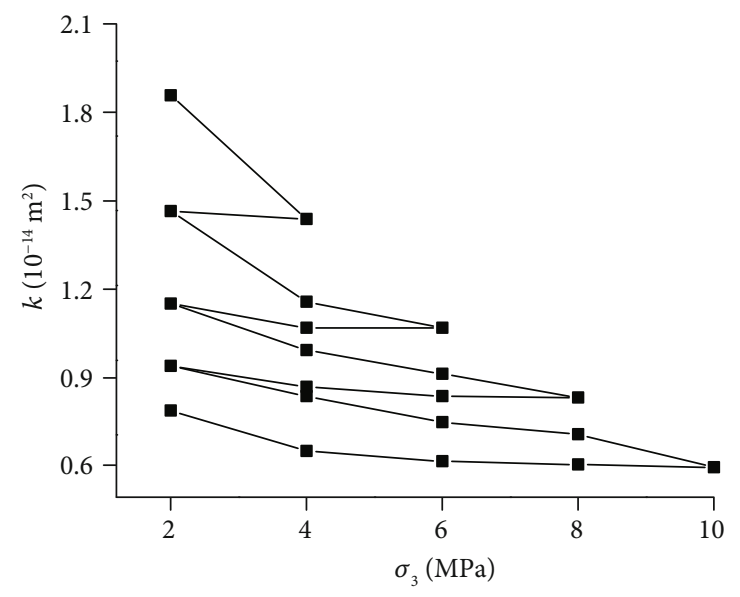

(a) X-1.72\%

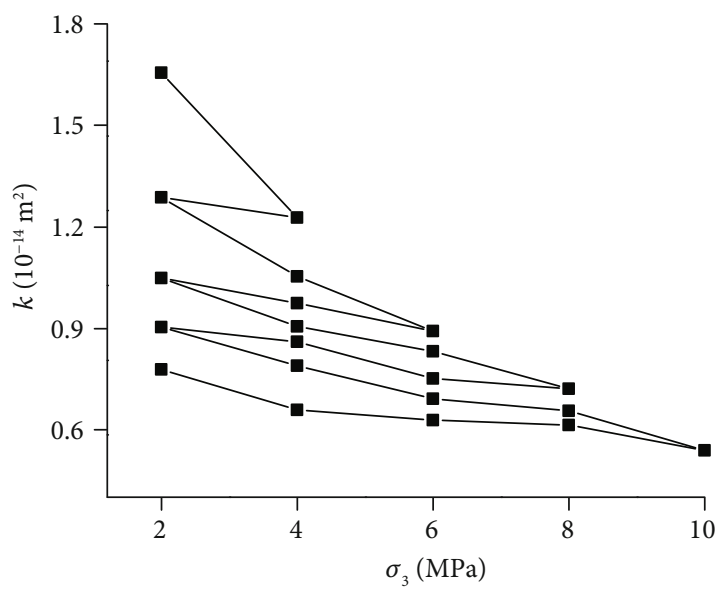

(b) $\mathrm{L}-1.72 \%$

FIGURE 16: The permeability evolution during the loading-unloading process with the axial strain $1.72 \%$.

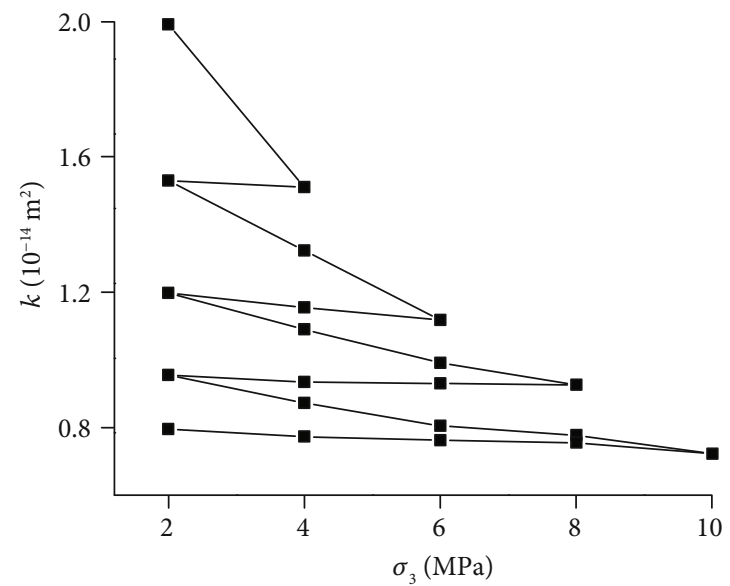

(a) X-1.79\%

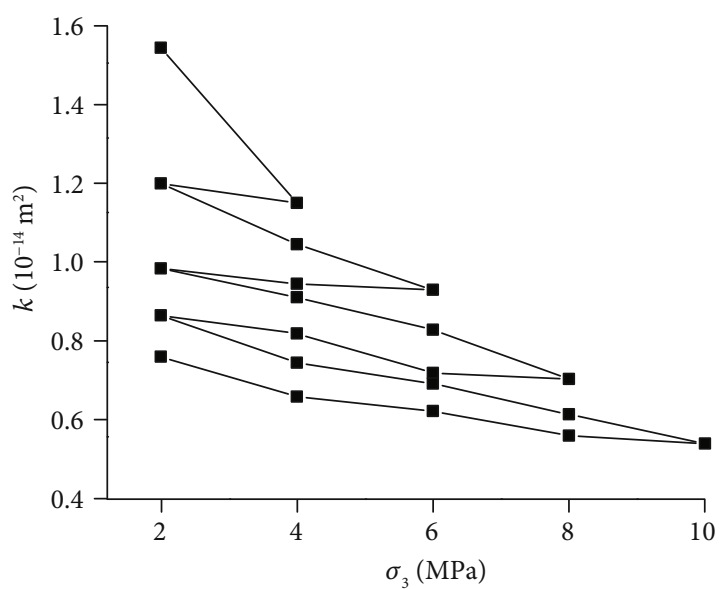

(b) $\mathrm{L}-1.79 \%$

FIGURE 17: The permeability evolution during the loading-unloading process with the axial strain $1.79 \%$. 


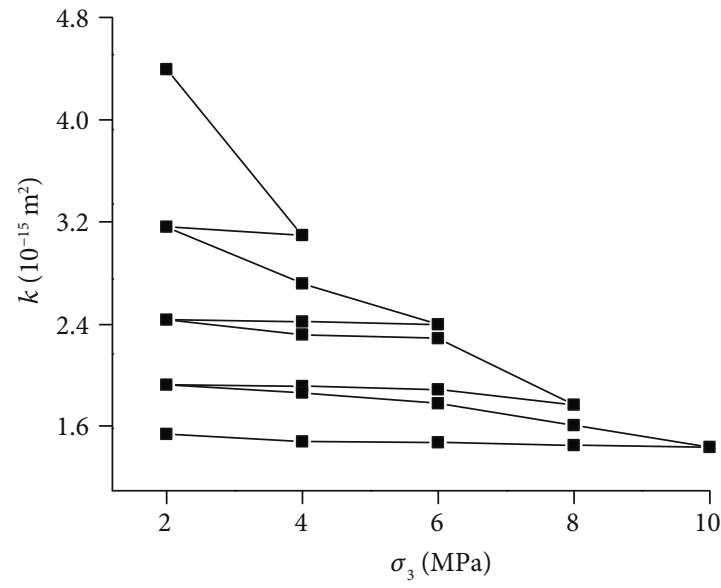

(a) $\mathrm{X}-1.81 \%$

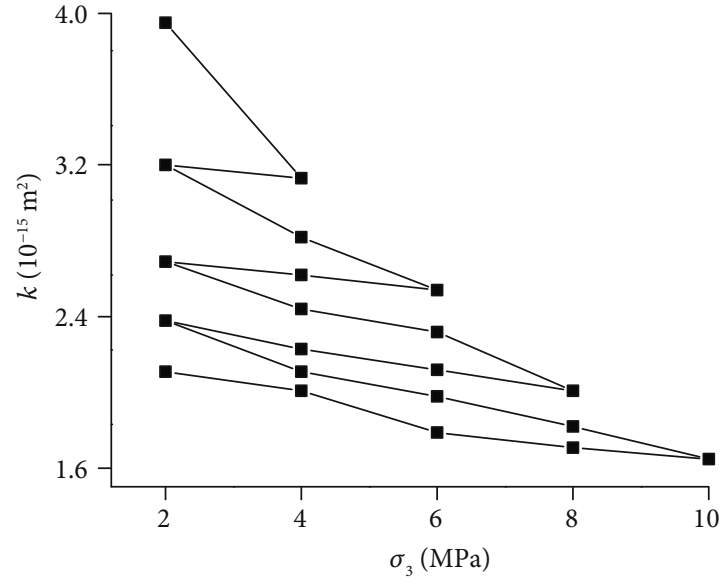

(b) $\mathrm{L}-1.81 \%$

FIGURE 18: The permeability evolution during the loading-unloading process with the axial strain $1.81 \%$.

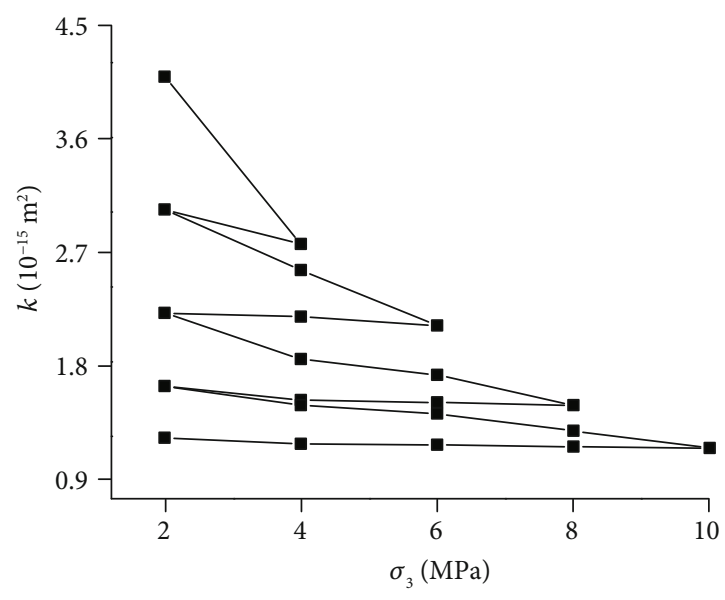

(a) $\mathrm{X}-2.01 \%$

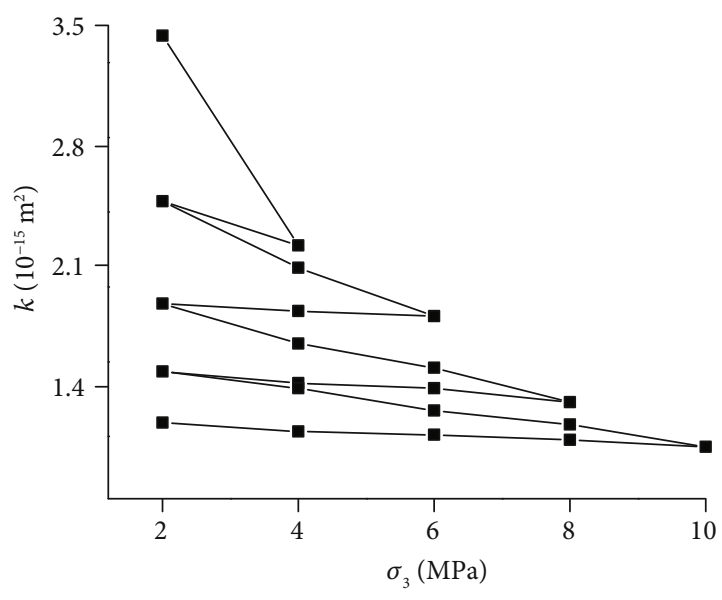

(b) $\mathrm{L}-2.01 \%$

FIGURE 19: The permeability evolution during the loading-unloading process with the axial strain $2.01 \%$.

TABLE 6: The permeability evolution during the loading-unloading process with the axial strain $1.61 \%$.

\begin{tabular}{lcccc}
\hline Permeability & $\mathrm{X}-K_{b}{ }^{(i)}\left(\mathrm{m}^{2}\right)$ & $\mathrm{X}-K_{r}{ }^{(i)}\left(\mathrm{m}^{2}\right)$ & $\mathrm{L}-K_{b}{ }^{(i)}\left(\mathrm{m}^{2}\right)$ & $2.24 E-14$ \\
\hline $2 \mathrm{MPa} \longrightarrow 4 \mathrm{MPa}$ & $2.48 E-14$ & $1.97 E-14$ & $1.79 E-14$ & $1.72 E-14$ \\
$2 \mathrm{MPa} \longrightarrow 6 \mathrm{MPa}$ & $1.98 E-14$ & $1.62 E-14$ & $1.37 E-14$ \\
$2 \mathrm{MPa} \longrightarrow 8 \mathrm{MPa}$ & $1.68 E-14$ & $1.27 E-14$ & $1.58 E-14$ & $1.11 E-14$ \\
$2 \mathrm{MPa} \longrightarrow 10 \mathrm{MPa}$ & $1.41 E-14$ & $9.92 E-15$ & $1.40 E-14$ & $9.48 E-15$ \\
\hline
\end{tabular}

TABLE 7: The permeability evolution during the loading-unloading process with the axial strain $1.72 \%$.

\begin{tabular}{|c|c|c|c|c|}
\hline Permeability & $\mathrm{X}-K_{b}^{(i)}\left(\mathrm{m}^{2}\right)$ & $\mathrm{X}-K_{r}{ }^{(i)}\left(\mathrm{m}^{2}\right)$ & $\mathrm{L}-K_{b}{ }^{(i)}\left(\mathrm{m}^{2}\right)$ & $\mathrm{L}-K_{r}{ }^{(i)}\left(\mathrm{m}^{2}\right)$ \\
\hline $2 \mathrm{MPa} \longrightarrow 4 \mathrm{MPa}$ & $1.86 E-14$ & $1.44 E-14$ & $1.65 E-14$ & $1.22 E-14$ \\
\hline $2 \mathrm{MPa} \longrightarrow 6 \mathrm{MPa}$ & $1.47 E-14$ & $1.07 E-14$ & $1.28 E-14$ & $1.05 E-14$ \\
\hline $2 \mathrm{MPa} \longrightarrow 8 \mathrm{MPa}$ & $1.15 E-14$ & $8.36 E-15$ & $1.05 E-14$ & $7.22 E-15$ \\
\hline $2 \mathrm{MPa} \longrightarrow 10 \mathrm{MPa}$ & $9.44 E-15$ & $6.01 E-15$ & $9.04 E-15$ & $5.41 E-15$ \\
\hline
\end{tabular}


TABLE 8: The permeability evolution during the loading-unloading process with the axial strain $1.79 \%$.

\begin{tabular}{lcccc}
\hline Permeability & $\mathrm{X}-K_{b}{ }^{(i)}\left(\mathrm{m}^{2}\right)$ & $\mathrm{X}-K_{r}{ }^{(i)}\left(\mathrm{m}^{2}\right)$ & $\mathrm{L}-K_{b}{ }^{(i)}\left(\mathrm{m}^{2}\right)$ & $1.47 E-14$ \\
\hline $2 \mathrm{MPa} \longrightarrow 4 \mathrm{MPa}$ & $1.99 E-14$ & $1.51 E-14$ & $1.07 E-14$ & $1.02 E-14$ \\
$2 \mathrm{MPa} \longrightarrow 6 \mathrm{MPa}$ & $1.53 E-14$ & $1.12 E-14$ & $8.74 E-15$ & $8.51 E-15$ \\
$2 \mathrm{MPa} \longrightarrow 8 \mathrm{MPa}$ & $1.20 E-14$ & $9.26 E-15$ & $7.53 E-15$ & $6.02 E-15$ \\
$2 \mathrm{MPa} \longrightarrow 10 \mathrm{MPa}$ & $9.55 E-15$ & $7.23 E-15$ & $4.51 E-15$ \\
\hline
\end{tabular}

TABLE 9: The permeability evolution during the loading-unloading process with the axial strain $1.81 \%$.

\begin{tabular}{lcccc}
\hline Permeability & $\mathrm{X}-K_{b}{ }^{(i)}\left(\mathrm{m}^{2}\right)$ & $\mathrm{X}-K_{r}{ }^{(i)}\left(\mathrm{m}^{2}\right)$ & $\mathrm{L}-K_{b}{ }^{(i)}\left(\mathrm{m}^{2}\right)$ & $\mathrm{L}-K_{r}{ }^{(i)}\left(\mathrm{m}^{2}\right)$ \\
\hline $2 \mathrm{MPa} \longrightarrow 4 \mathrm{MPa}$ & $4.39 E-15$ & $3.09 E-15$ & $3.96 E-15$ & $3.13 E-15$ \\
$2 \mathrm{MPa} \longrightarrow 6 \mathrm{MPa}$ & $3.16 E-15$ & $2.39 E-15$ & $3.17 E-15$ & $2.54 E-15$ \\
$2 \mathrm{MPa} \longrightarrow 8 \mathrm{MPa}$ & $2.44 E-15$ & $1.77 E-15$ & $2.62 E-15$ & $1.89 E-15$ \\
$2 \mathrm{MPa} \longrightarrow 10 \mathrm{MPa}$ & $1.93 E-15$ & $1.44 E-15$ & $2.28 E-15$ & $1.62 E-15$ \\
\hline
\end{tabular}

TABLE 10: The permeability evolution during the loading-unloading process with the axial strain $2.01 \%$.

\begin{tabular}{lcccc}
\hline Permeability & $\mathrm{X}-K_{b}{ }^{(i)}\left(\mathrm{m}^{2}\right)$ & $\mathrm{X}-K_{r}{ }^{(i)}\left(\mathrm{m}^{2}\right)$ & $\mathrm{L}-K_{b}{ }^{(i)}\left(\mathrm{m}^{2}\right)$ & $\mathrm{L}-K_{r}{ }^{(i)}\left(\mathrm{m}^{2}\right)$ \\
\hline $2 \mathrm{MPa} \longrightarrow 4 \mathrm{MPa}$ & $4.09 E-15$ & $2.76 E-15$ & $3.44 E-15$ & $2.22 E-15$ \\
$2 \mathrm{MPa} \longrightarrow 6 \mathrm{MPa}$ & $3.04 E-15$ & $2.12 E-15$ & $2.48 E-15$ & $1.81 E-15$ \\
$2 \mathrm{MPa} \longrightarrow 8 \mathrm{MPa}$ & $2.22 E-15$ & $1.49 E-15$ & $1.88 E-15$ & $1.31 E-15$ \\
$2 \mathrm{MPa} \longrightarrow 10 \mathrm{MPa}$ & $1.64 E-15$ & $1.15 E-15$ & $1.49 E-15$ & $1.05 E-15$ \\
\hline
\end{tabular}

TABle 11: The confining pressure influence coefficient of waterbearing specimen.

\begin{tabular}{lcccc}
\hline & \multicolumn{4}{c}{ Confining pressure influence } \\
Axial strain (\%) & $\gamma_{1}^{(1)}$ & $\gamma_{1}^{(2)}$ & $\Upsilon_{1}^{(3)}$ & $\Upsilon_{1}^{(4)}$ \\
\hline $\mathrm{X}-1.61$ & 0.26 & 0.09 & 0.068 & 0.052 \\
$\mathrm{X}-1.72$ & 0.24 & 0.12 & 0.052 & 0.043 \\
$\mathrm{X}-1.79$ & 0.21 & 0.10 & 0.046 & 0.029 \\
$\mathrm{X}-1.81$ & 0.065 & 0.019 & 0.011 & 0.0061 \\
$\mathrm{X}-2.01$ & 0.067 & 0.023 & 0.012 & 0.0059 \\
\hline
\end{tabular}

TABLE 12: The confining pressure influence coefficient of nonwater specimen.

\begin{tabular}{lcccc}
\hline & \multicolumn{4}{c}{ Confining pressure influence } \\
Axial strain (\%) & \multicolumn{4}{c}{ coefficient $\Upsilon_{1}^{(\mathrm{i})}$} \\
& $\Upsilon_{1}^{(1)}$ & $\Upsilon_{1}^{(2)}$ & $\gamma_{1}^{(3)}$ & $\Upsilon_{1}^{(4)}$ \\
\hline L-1.61 & 0.26 & 0.11 & 0.078 & 0.057 \\
L-1.72 & 0.22 & 0.058 & 0.055 & 0.046 \\
L-1.79 & 0.21 & 0.055 & 0.045 & 0.038 \\
L-1.81 & 0.042 & 0.016 & 0.012 & 0.0082 \\
L-2.01 & 0.061 & 0.017 & 0.0095 & 0.0055 \\
\hline
\end{tabular}

the perspective of the primary fissure, the SEM and mercury intrusion tests show that a large number of primary cracks with large opening are observed are observed in the Xiaojihan coal sample, and the average pore size of the Xiaojihan
TABLE 13: The permeability recovery coefficient of water-bearing specimen.

\begin{tabular}{lllll}
\hline \multirow{2}{*}{ Axial strain (\%) } & \multicolumn{4}{c}{ Permeability recovery coefficient } \\
& $\Upsilon_{2}^{(1)}$ & $\Upsilon_{2}^{(2)}$ & $\Upsilon_{2}^{(3)}$ & $\Upsilon_{2}^{(4)}$ \\
\hline X-1.61 & 0.80 & 0.84 & 0.85 & 0.86 \\
X-1.72 & 0.79 & 0.78 & 0.82 & 0.84 \\
X-1.79 & 0.77 & 0.78 & 0.80 & 0.83 \\
X-1.81 & 0.72 & 0.77 & 0.79 & 0.81 \\
X-2.01 & 0.74 & 0.73 & 0.74 & 0.75 \\
\hline
\end{tabular}

TABLE 14: The permeability recovery coefficient of nonwater specimen.

\begin{tabular}{|c|c|c|c|c|}
\hline \multirow{2}{*}{ Axial strain (\%) } & \multicolumn{4}{|c|}{ Permeability recovery coefficient $Y_{2}^{(\mathrm{i})}$} \\
\hline & $\gamma_{2}^{(1)}$ & $\gamma_{2}^{(2)}$ & $\Upsilon_{2}^{(3)}$ & $Y_{2}^{(4)}$ \\
\hline $\mathrm{L}-1.61$ & 0.80 & 0.88 & 0.89 & 0.93 \\
\hline $\mathrm{L}-1.72$ & 0.78 & 0.82 & 0.86 & 0.90 \\
\hline $\mathrm{L}-1.79$ & 0.73 & 0.82 & 0.86 & 0.89 \\
\hline $\mathrm{L}-1.81$ & 0.80 & 0.81 & 0.87 & 0.89 \\
\hline $\mathrm{L}-2.01$ & 0.72 & 0.76 & 0.79 & 0.80 \\
\hline
\end{tabular}

coal specimen is greater than that of the Longde coal specimen. The results show that the water storage capacity of the Xiaojihan coal seam is stronger than that of the Longde coal seam. 


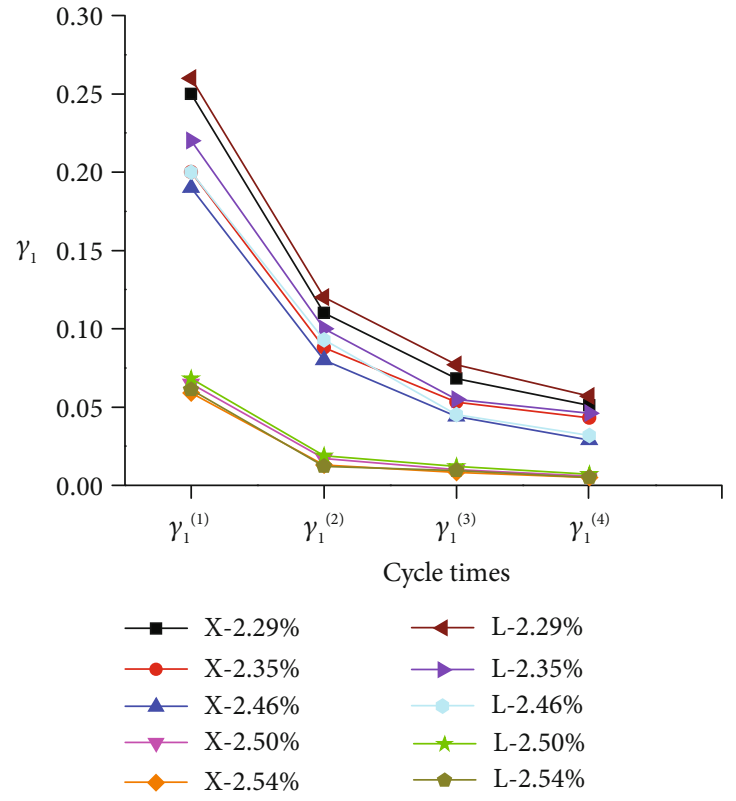

(a) Confining pressure influence coefficient

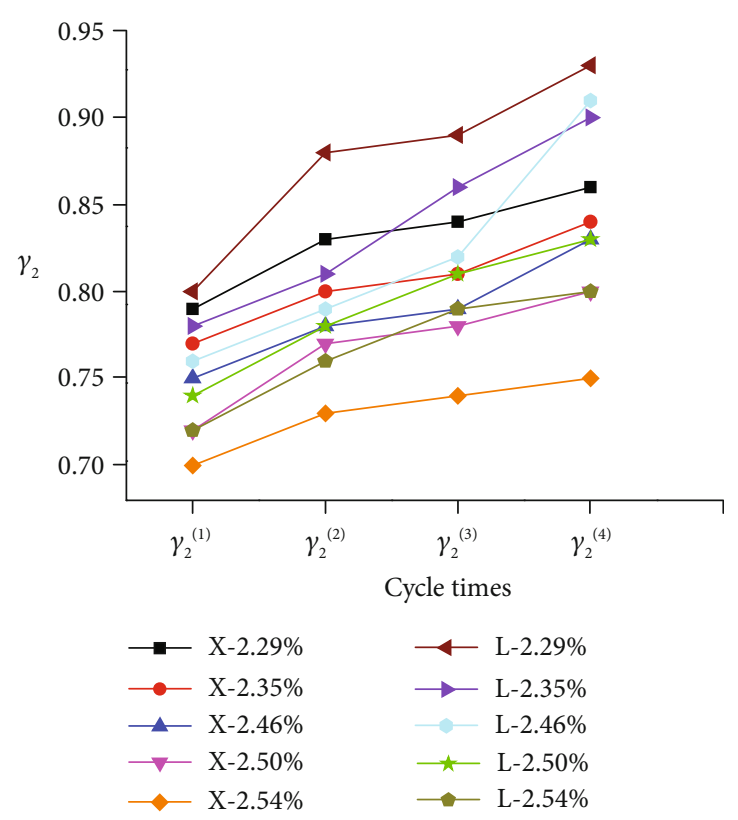

(b) Permeability recovery coefficient

Figure 20: The comparison of the confining pressure influence coefficient and permeability recovery coefficient between two kinds of specimens.

\section{Conclusions}

In view of the special geological structure of the "coal seam in the western mining area as the main aquifer," the permeability tests of the Xiaojihan coal specimens and Longde coal specimens under plastic flow are conducted. The main conclusions are obtained as follows.

(1) The relation between confining pressure and coal permeability is negative exponential. The permeability, relative residual strain, and confining pressure influence coefficient of Xiaojihan coal specimens all decrease with the increase of loading-unloading times and confining pressure. However, the influence of confining pressure on coal permeability during the second loading process is much weaker than that during the first loading process. The plastic deformation is mainly produced during the first loading and unloading process, while the water-bearing coal specimens are mainly subjected to neutral loading in the last three loading and unloading processes, which is the elastic deformation after plastic deformation. The plasticity produced with an increase in the number of times of confining pressure loading and unloading is reduced, and the influence on the permeability is reduced

(2) The permeability, confining pressure influence coefficient, and permeability recovery coefficient of the water-bearing coal specimen decrease with the axial strain, but the relative residual strain increases with the axial strain. It is indicated that the plastic deformation of the coal sample increases, and the influence of the confining pressure on the permeability decreases with the axial strain
(3) The reasons for the main aquifer of the Xiaojihan coal seam are mainly explained in the following aspects. First, the Xiaojihan coal seam contains plenty of primary cracks with wider width and strong capacity of water storage. Second, the permeability of the Xiaojihan coal specimen is greater than that of the Longde coal specimen; thus, water from roof strata is more likely to penetrate into Xiaojihan coal seams. Besides, the confining pressure influence coefficient and permeability recovery coefficient of Xiaojihan coal specimens are smaller than those of Longde specimens, which indicates that the permeability of the Xiaojihan coal specimen is more insensitive to the change of stress. In the process of periodic displacement of the coal seam, the closure rate of internal cracks of the Xiaojihan coal specimen is lower than that of the Longde coal specimen, which is beneficial for water storage and transport. Those are the main reasons of Xiaojihan coal seams as the main aquifer

The plastic behavior of coal specimens from the coal seam as the main aquifer is extremely obvious. This paper mainly studies the variation of permeability of the aquifer with confining pressure and axial strain under plastic flow. However, the theoretical relationship between stress (strain) and permeability under different paths in plastic flow is subject to study in the future.

\section{Data Availability}

The data used in the manuscript is from experiment. you can contact Jingna Guo (tb18030001b4@cumt.edu.cn) if you want learn more about our work. 


\section{Conflicts of Interest}

The authors declare no conflict of interest.

\section{Acknowledgments}

The authors are grateful for the support provided by the Fundamental Research Funds for the Central Universities (China University of Mining and Technology) (2019XKQYMS19).

\section{References}

[1] C. Zhang, S. Tu, and L. Zhang, "Analysis of broken coal permeability evolution under cyclic loading and unloading conditions by the model based on the Hertz contact deformation principle," Transport in Porous Media, vol. 119, no. 3, pp. 739-754, 2017.

[2] D. Li, Z. Sun, T. Xie, X. Li, and P. G. Ranjith, "Energy evolution characteristics of hard rock during triaxial failure with different loading and unloading paths," Engineering Geology, vol. 228, pp. 270-281, 2017.

[3] E. Liu, R. Huang, and S. He, "Effects of frequency on the dynamic properties of intact rock samples subjected to cyclic loading under confining pressure conditions," Rock Mechanics and Rock Engineering, vol. 45, no. 1, pp. 89-102, 2012.

[4] Z. Wang, S. Li, L. Qiao, and J. Zhao, "Fatigue behavior of granite subjected to cyclic loading under triaxial compression condition," Rock Mechanics and Rock Engineering, vol. 46, no. 6, pp. 1603-1615, 2013.

[5] N. J. Zhu, B. Y. Li, and D. Y. Hao, "Study on prevention and control technology of mine water damage in main aquifer of coal seam," China Mining Magazine, vol. 25, no. 3, pp. 8690, 2016.

[6] F. Zhang, S. Y. Xie, D. W. Hu, J. F. Shao, and B. Gatmiri, "Effect of water content and structural anisotropy on mechanical property of claystone," Applied Clay Science, vol. 69, pp. 7986, 2012.

[7] D. Li, L. N. Y. Wong, G. Liu, and X. Zhang, "Influence of water content and anisotropy on the strength and deformability of low porosity meta-sedimentary rocks under triaxial compression," Engineering Geology, vol. 126, pp. 46-66, 2012.

[8] F. Valès, D. Nguyen Minh, H. Gharbi, and A. Rejeb, "Experimental study of the influence of the degree of saturation on physical and mechanical properties in Tournemire shale (France)," Applied Clay Science, vol. 26, no. 1-4, pp. 197-207, 2004.

[9] J. Chao, M. Yu, T. Chu, X. Han, F. Teng, and P. Li, "Evolution of broken coal permeability under the condition of stress, temperature, moisture content, and pore pressure," Rock Mechanics and Rock Engineering, vol. 52, no. 8, pp. 2803-2814, 2019.

[10] Y. Zhao, J. Tang, Y. Chen et al., "Hydromechanical coupling tests for mechanical and permeability characteristics of fractured limestone in complete stress-strain process," Environmental Earth Sciences, vol. 76, no. 1, 2017.

[11] L. D. Connell, M. Lu, and Z. Pan, "An analytical coal permeability model for tri-axial strain and stress conditions," International Journal of Coal Geology, vol. 84, no. 2, pp. 103-114, 2010.

[12] D. Ma, X. X. Miao, G. H. Jiang, H. B. Bai, and Z. Q. Chen, “An experimental investigation of permeability measurement of water flow in crushed rocks," Transport in Porous Media, vol. 105, no. 3, pp. 571-595, 2014.
[13] L. Wang, J. F. Liu, J. L. Pei, H. N. Xu, and Y. Bian, "Mechanical and permeability characteristics of rock under hydromechanical coupling conditions," Environmental Earth Sciences, vol. 73, no. 10, pp. 5987-5996, 2015.

[14] B. Y. Zhang, H. B. Bai, and K. Zhang, "Research on permeability characteristics of karst collapse column fillings in complete stress-strain process," Journal of Mining \& Safety Engineering, vol. 33, pp. 734-740, 2016.

[15] Q. Lyu, J. Tan, J. M. Dick et al., "Stress-strain modeling and brittleness variations of low-clay shales with $\mathrm{CO} 2 / \mathrm{CO} 2$-water imbibition," Rock Mechanics and Rock Engineering, vol. 52, no. 7, pp. 2039-2052, 2019.

[16] C. Jiang, M. Duan, G. Yin et al., "Experimental study on seepage properties, $\mathrm{AE}$ characteristics and energy dissipation of coal under tiered cyclic loading," Engineering Geology, vol. 221, pp. 114-123, 2017.

[17] J. Zou, W. Chen, D. Yang, H. Yu, and J. Yuan, “The impact of effective stress and gas slippage on coal permeability under cyclic loading," Journal of Natural Gas Science and Engineering, vol. 31, pp. 236-248, 2016.

[18] N. N. Danesh, Z. Chen, L. D. Connell, M. S. Kizil, Z. Pan, and S. M. Aminossadati, "Characterisation of creep in coal and its impact on permeability: An experimental study," International Journal of Coal Geology, vol. 173, pp. 200-211, 2017.

[19] Q. L. Ding, F. Ju, S. B. Song, B. Y. Yu, and D. Ma, “An experimental study of fractured sandstone permeability after hightemperature treatment under different confining pressures," Journal of Natural Gas Science and Engineering, vol. 34, pp. 55-63, 2016.

[20] A. M. Shar, A. A. Mahesar, A. D. Chandio, and K. R. Memon, "Impact of confining stress on permeability of tight gas sands: an experimental study," Journal of Petroleum Exploration and Production Technology, vol. 7, no. 3, pp. 717-726, 2017.

[21] Y. Wang, L. Jeannin, F. Agostini, L. Dormieux, F. Skoczylas, and E. Portier, "Experimental study and micromechanical interpretation of the poroelastic behaviour and permeability of a tight sandstone," International Journal of Rock Mechanics and Mining Sciences, vol. 103, pp. 89-95, 2018.

[22] A. P. S. Selvadurai and A. Głowacki, "Permeability hysterisis of limestone during isotropic compression," Ground Water, vol. 46, pp. 113-119, 2008.

[23] D. M. Zhang, Y. S. Yang, Y. P. Chu, X. Zhang, and Y. G. Xue, "Influence of loading and unloading velocity of confining pressure on strength and permeability characteristics of crystalline sandstone," Results in Physics, vol. 9, pp. 13631370, 2018.

[24] T. Deng, T. Li, D. Qiao, and K. Li, "Research on mechanical and gas seepage characteristics of coal-containing gas in the process of unloading confining pressure before and after peak strength," Materials Research Innovations, vol. 19, no. sup8, pp. S8-611-S8-618, 2015.

[25] C. Jiang, G. Yin, W. Li, and Q. Huang, "Experimental of mechanical properties and gas flow of containing-gas coal under different unloading speeds of confining pressure," Procedia Engineering, vol. 26, pp. 1380-1384, 2011.

[26] Z. Meng, J. Zhang, and R. Wang, "In-situ stress, pore pressure and stress-dependent permeability in the Southern Qinshui Basin," International Journal of Rock Mechanics and Mining Sciences, vol. 48, no. 1, pp. 122-131, 2011.

[27] Q. J. Zhu, Y. H. Chen, and J. Chen, "Influence of underground faults and fracture distribution on liquid movement," Journal 
of Central South University of Technology, vol. 14, no. S1, pp. 454-457, 2007.

[28] R. Gao, H. Yan, F. Ju, X. Mei, and X. Wang, "Influential factors and control of water inrush in a coal seam as the main aquifer," International Journal of Mining Science and Technology, vol. 28, no. 2, pp. 187-193, 2018.

[29] H. Li, "Research on seepage properties and pore structure of the roof and floor strata in confined water-rich coal seams: taking the Xiaojihan coal mine as an example," Advances in Civil Engineering, vol. 2018, 8 pages, 2018.

[30] S. C. Li, Q. Li, X. X. Miao, and Z. Q. Chen, "Formation medium permeability characteristics of Xiaojihan well field and genesis mechanism of coal-bearing aquifer," Journal of China Coal Society, vol. 2, 2017.

[31] X. B. Wang and Y. S. Pan, "Simulation of rock burst process in circular roadway under different lateral pressure coefficients," Geotechnical Mechanics, vol. 6, pp. 260-265, 2010.

[32] F. Homand, A. Giraud, S. Escoffier, A. Koriche, and D. Hoxha, "Permeability determination of a deep argillite in saturated and partially saturated conditions," International Journal of Heat and Mass Transfer, vol. 47, no. 14-16, pp. 3517-3531, 2004.

[33] H. Song, H. Zhang, D. Fu et al., "Experimental study on damage evolution of rock under uniform and concentrated loading conditions using digital image correlation," Fatigue \& Fracture of Engineering Materials \& Structures, vol. 36, no. 8, pp. 760768, 2013.

[34] X. U. Demin, "Experimental study on permeability of porous media under high confining pressure," Journal of Engineering Geology, vol. 15, no. 6, pp. 752-756, 2007. 